Check for updates

Cite this: Phys. Chem. Chem. Phys., 2020, 22, 15248

Received 17th December 2019, Accepted 17th March 2020

DOI: $10.1039 / c 9 c p 06795 \mathrm{~g}$

rsc.li/pccp

\section{Predictive models for the phase behaviour and solution properties of weak electrolytes: nitric, sulphuric, and carbonic acids}

\author{
Maximilian Kohns, ${ }^{\text {ab }}$ Georgia Lazarou, ${ }^{a}$ Spiros Kournopoulos, ${ }^{a}$ Esther Forte, ${ }^{\text {ac }}$ \\ Felipe A. Perdomo, ${ }^{a}$ George Jackson, iD a Claire S. Adjiman iD a and \\ Amparo Galindo (iD *a
}

\begin{abstract}
The distribution of ionic species in electrolyte systems is important in many fields of science and engineering, ranging from the study of degradation mechanisms to the design of systems for electrochemical energy storage. Often, other phenomena closely related to ionic speciation, such as ion pairing, clustering and hydrogen bonding, which are difficult to investigate experimentally, are also of interest. Here, we develop an accurate molecular approach, accounting for reactions as well as association and ion pairing, to deliver a predictive framework that helps validate experiment and guides future modelling of speciation phenomena of weak electrolytes. We extend the SAFT-VRE Mie equation of state [D. K. Eriksen et al., Mol. Phys., 2016, 114, 2724-2749] to study aqueous solutions of nitric, sulphuric, and carbonic acids, considering complete and partially dissociated models. In order to incorporate the dissociation equilibria, correlations to experimental data for the relevant thermodynamic equilibrium constants of the dissociation reactions are taken from the literature and are imposed as a boundary condition in the calculations. The models for water, the hydronium ion, and carbon dioxide are treated as transferable and are taken from our previous work. We present new molecular models for nitric acid, and the nitrate, bisulfate, sulfate, and bicarbonate anions. The resulting framework is used to predict a range of phase behaviour and solution properties of the aqueous acids over wide ranges of concentration and temperature, including the degree of dissociation, as well as the activity coefficients of the ionic species, and the activity of water and osmotic coefficient, density, and vapour pressure of the solutions. The SAFT-VRE Mie models obtained in this manner provide a means of elucidating the mechanisms of association and ion pairing in the systems studied, complementing the experimental observations reported in the literature.
\end{abstract}

\section{Introduction}

Many applications involving liquid solutions relate to degradation, the reaction between compounds and, in general, to the formation of new species. In such systems the thermodynamic description of equilibrium, which necessarily requires the complete characterisation of the existing substances and their interactions also means accounting for any occurring speciation. In relation to electrolyte solutions, thermodynamic modelling with equations of state has been performed extensively for

\footnotetext{
${ }^{a}$ Department of Chemical Engineering, Centre for Process Systems Engineering and Institute for Molecular Science and Engineering, South Kensington Campus, Imperial College London, London SW7 2AZ, UK.

E-mail: a.galindo@imperial.ac.uk; Tel: +44 (0)20 75945606

${ }^{b}$ Laboratory of Engineering Thermodynamics, Technische Universität Kaiserslautern, 67663 Kaiserslautern, Germany

${ }^{c}$ Evonik Technology \& Infrastructure GmbH, Rodenbacher Chaussee 4,

63457 Hanau-Wolfgang, Germany
}

strong electrolytes, yet remains rather more limited for solutions of partially dissociated electrolytes. The intermolecular interactions pertinent to charged species involve complex longand short-ranged forces, which are further compounded in weak electrolyte solutions by the consideration of dissociation equilibria as well as the higher likelihood of ion pairing. The characterisation of mixtures containing weak electrolytes is not trivial, requiring an explicit treatment of chemical reaction equilibria alongside the physical model. A general framework to model solutions of weak electrolytes is essentially that of a reactive system, although the calculation of the activities of the species present requires methods that incorporate a treatment of Coulombic (and often polar) interactions. Two challenges need to be addressed in order to model weak electrolytes: the first is to account for the reactive nature of the system alongside phase equilibrium; the second to achieve an appropriate description of the range of intermolecular interactions participating in the system. 
The development of methodologies to treat chemical equilibria has received much attention, since, as well as describing the formation of new chemical species, the concepts of chemical equilibria have been found to be useful in mimicking physical associations such as those in hydrogen-bonding fluids. ${ }^{1}$ Moreover, a number of approaches have been presented that describe the hydration of ions as chemical equilibria. ${ }^{2-5}$ Some of the interrelations and differences between the degree of physical or chemical association are discussed in an early paper by Guggenheim ${ }^{6}$ in 1960 through what he referred to as "sociation" and association, respectively. In the terrain of electrolytes, Guggenheim defined a degree of supersociation to characterise the association between ions through a modified equilibrium constant that establishes an infinitely dilute system as the reference to describe the fraction of ion pairs. In this way he aimed to avoid ambiguities in the definition of the limit demarcating associated ion pairs from free ions. ${ }^{6}$

The most widely used thermodynamic models for electrolyte solutions are activity coefficient models and consequently much of the modelling of weak electrolytes has been presented with this type of approaches. ${ }^{7}$ Typically, the thermodynamic equilibrium constant determined experimentally is employed in order to solve the required electrolyte dissociation equilibria in parallel with the phase equilibria. Much of the earlier work on weak electrolytes ${ }^{8-11}$ was performed using the electrolyte activity coefficient model of Pitzer, ${ }^{12}$ while subsequent approaches tended towards extending activity coefficient models for nonelectrolytes with the Debye-Hückel ${ }^{13}$ theory. For example, the e-NRTL model presented by Chen et al. ${ }^{14}$ combines the NRTL activity coefficient model of Renon and Prausnitz ${ }^{15}$ with the Debye-Hückel theory, and was applied to weak electrolytes by Austgen et al. ${ }^{16}$ and by Que and Chen. ${ }^{17}$ Similarly, the e-UNIFAC model presented by Achard et $a .^{18}$ is based on the UNIFAC group-contribution approach of Frendenslund et al. ${ }^{19}$ By supplementing e-UNIFAC with a numerical procedure to predict partial dissociation phenomena, Achard et $a .^{20}$ effectively modelled solutions of weak acids and bases. Wang et al. ${ }^{21}$ later applied the electrolyte-UNIQUAC model - which was first presented by Christensen et $a .^{22}$ - to model weak electrolytes in mixed solvents, and an interesting application of the electrolyte-UNIQUAC model was presented by Thomsen and co-workers, ${ }^{23,24}$ who modelled ternary mixtures containing mixed weak electrolytes by employing the electrolyte-UNIQUAC model for the liquid phase and the Soave-Redlich-Kwong equation of state ${ }^{25}$ for the vapour phase.

Although activity coefficient models have proven to be highly effective in reproducing the thermodynamic behaviour of electrolyte solutions, including multi-solvent and mixed-electrolyte mixtures containing weak electrolytes, an important drawback of these methods is that they require a large number of adjustable parameters. In this respect, equations of state have an advantage as thermodynamic modelling tools. Equations of state based on perturbation theories such as the perturbed hard-chain theory of Beret and Prausnitz ${ }^{26}$ and the perturbedanisotropic-chain theory of Vimalchand and Donohue ${ }^{27}$ were directly adapted to model electrolytes in the 1980s, with application to weak electrolytes presented by Daumn et $a .^{28}$ and by Jin and Donohue, ${ }^{29}$ respectively. In the context of perturbationbased equation of state approaches, the statistical associating fluid theory (SAFT) ${ }^{30,31}$ has been extensively applied to model electrolytes. In particular, the perturbed-chain SAFT for electrolytes (ePC-SAFT) of Cameretti et $a .^{32}$ has been most broadly applied to weak electrolytes. ${ }^{33-37}$ The method is based on the PC-SAFT equation of state ${ }^{38,39}$ with the addition of a Debye-Hückel term to account for the electrostatic interactions. In the first application of ePC-SAFT to weak electrolytes Held and Sadowski ${ }^{33}$ considered (among other weak electrolytes) weak acids that form ion pairs. A chemical model for ion pairing was employed, and the ion pairs were modelled as distinct species with no net charge. Reschke et al. ${ }^{34}$ later used ePC-SAFT to model the stepwise dissociation of multiprotic weak acids, while Cassens et al. ${ }^{35}$ implemented ePC-SAFT to study the aqueous solubility of weak bases in response to a pH-changing agent.

The SAFT equation of state for square-well potentials of variable range (SAFT-VR SW) ${ }^{40,41}$ was extended to treat electrolyte solutions early on ${ }^{42,43}$ and was shown to be useful for the prediction of salting out in mixtures of water and alkanes. ${ }^{44}$ The implementation of this SAFT-VRE SW equation of state to weak electrolytes has thus far been limited to the work of Paricaud et al., ${ }^{45}$ in which the phase equilibrium of aqueous hydrogen iodide was modelled in parallel with the dissociation and reaction equilibria of the system. The SAFT-VRE SW approach has been revised recently ${ }^{46}$ to incorporate a Born ${ }^{47}$ solvation energy contribution to deliver solvation free energies which are physically relevant and to allow for salt partitioning in liquid-liquid equilibria. In a similar vein, Coulombic and Born terms have been included in the SAFT-VRE Mie equation of state $^{48}$ (an extension of the SAFT-VR Mie equation of state ${ }^{49}$ to model electrolyte solutions). Taking an ion-specific modelling approach and requiring only one adjustable parameter per ion, the SAFT-VRE Mie approach was applied to model a wide range of thermophysical properties of aqueous solutions of strong electrolytes, including hydration free energies, mean-ionic coefficients, osmotic coefficients and solubility limits for a range of strong electrolytes. In our current paper we use the SAFT-VRE Mie equation of state to model weak electrolytes. A similar framework can be applied with the SAFT- $\gamma$ Mie group contribution approach, ${ }^{50-52}$ following appropriate mappings to incorporate the ionic free energy contributions.

The focus of our current work is on aqueous solutions of three inorganic acids of fundamental importance in industrial applications, namely sulphuric, nitric, and carbonic acids. Their dissociation equilibria have been well characterised experimentally. We couple the experimental data for the equilibrium constant of the dissociation reaction with the SAFT-VRE Mie approach $^{50}$ to obtain a reliable equation-of-state-based model for these acids. Experimental data of the degree of dissociation of the three acids in aqueous solution are readily available and are used to determine the adjustable parameters in our model. In contrast, only limited quantitative information regarding the nature of ion-ion association or ion pairing and ion-water hydrogen bonding interactions can be found in the literature. The SAFT-VRE Mie approach provides an opportunity to test 
different association schemes and to thereby elucidate which types of interactions have a governing impact on the thermodynamic behaviour of these systems.

We first provide a concise review on the thermodynamics of (weak) electrolytes (Section 2), including the treatment of the dissociation equilibrium. This is followed by an overview of the SAFT-VRE Mie theory in Section 3 and a description of the molecular models employed therein. We first consider the case of aqueous sulphuric acid and present our proposed model (Section 4), which is developed in light of experimental information for ion hydration and ion association phenomena. Aqueous nitric acid is studied in Section 5. We consider modelling approaches treating the acid as both a strong and a weak electrolyte, as a means of evaluating the relative benefit of the latter approach for electrolytes which dissociate appreciably albeit not completely. In Section 6, results for aqueous carbonic acid are presented. Conclusions are provided in Section 7 .

\section{Thermodynamics of weak electrolytes}

\subsection{Dissociation, true and overall composition}

Consider the (possibly incomplete) dissociation of a salt $\mathrm{A}_{\nu_{\mathrm{A}}} \mathbf{B}_{\nu_{\mathrm{B}}}$ into its constituent ions $\mathrm{A}^{z{ }^{+}}$and $\mathrm{B}^{z^{B^{-}}}$in a solvent $\mathrm{W}$ :

$$
\mathrm{A}_{\nu_{\mathrm{A}}} \mathrm{B}_{\nu_{\mathrm{B}}} \stackrel{K_{\mathrm{a}}}{\rightleftharpoons} \nu_{\mathrm{A}} \mathrm{A}^{z_{\mathrm{A}^{+}}}+\nu_{\mathrm{B}} \mathrm{B}^{z_{\mathrm{B}^{-}}} .
$$

For ease of notation, the stoichiometric coefficient indices $\nu_{\mathrm{A}}$ and $\nu_{\mathrm{B}}$ in the salt $\mathrm{A}_{\nu_{\mathrm{A}}} \mathrm{B}_{\nu_{\mathrm{B}}}$ are dropped in the following analysis, and only + and - are written as exponents of the ions instead of the charge numbers $z_{\mathrm{A}^{+}}$and $z_{\mathrm{B}^{-}}$.

Suppose a solution of $\mathrm{AB}$ is prepared by mixing $\tilde{n}_{\mathrm{AB}}$ moles $\mathrm{AB}$ with $\tilde{n}_{\mathrm{W}}$ moles of solvent. These two numbers of moles represent the 'overall' composition of the solution; always indicated by a tilde $(\sim)$ in this work. By virtue of the dissociation reaction however, the 'true' composition of the solution at any given temperature $T$ and pressure $p$ is specified by the numbers of moles of the undissociated salt $n_{\mathrm{AB}}$, solvent $n_{\mathrm{W}}$, cation $n_{\mathrm{A}^{+}}$ and anion $n_{\mathrm{B}^{-}}$. (This distinction of 'overall' and 'true' values pertains also other thermodynamic properties, especially the chemical potential and related properties, $c f$. Section 2.3.) The 'overall' and 'true' compositions are related through the material balances. Here,

$$
\begin{gathered}
n_{\mathrm{A}^{+}}=\nu_{\mathrm{A}} \xi \\
n_{\mathrm{B}^{-}}=\nu_{\mathrm{B}} \xi \\
n_{\mathrm{AB}}=\tilde{n}_{\mathrm{AB}}-\xi,
\end{gathered}
$$

where $\xi$ is the molar extent of reaction. Instead of the molar extent of reaction, the degree of dissociation $\alpha$ is often used:

$$
\alpha=\frac{\xi}{\tilde{n}_{\mathrm{AB}}},
$$

where $\xi$, or $\alpha$, respectively, are computed from the condition of chemical equilibrium.

\subsection{Dissociation equilibrium}

At specified temperature $T$ and pressure $p$ the total Gibbs free energy of a mixture is given by

$$
G(T, p, \mathbf{n})=\sum_{i=1}^{N} n_{i} \mu_{i}
$$

where $N$ is the number of components, $\mathbf{n}$ is the vector of mole numbers of these components, $\mu_{i}$ is the chemical potential of component $i$ in the mixture, and a single phase is assumed. As discussed earlier, a reaction will lead to changes in the mole numbers, and

$$
\mathrm{d} G(T, p, \mathbf{n})=\sum_{i=1}^{N}\left(\nu_{i} d \xi\right) \mu_{i}
$$

where, $\nu_{i}<0$ for reactants and $\nu_{i}>0$ for products. The necessary condition for equilibrium in a closed system specifies the derivative of the Gibbs free energy be zero with respect to the extent of reaction $\xi$, resulting in

$$
\sum_{i=1}^{N} \nu_{i} \mu_{i}=0
$$

which when applied to the dissociation presented in the previous section leads to

$$
\nu_{\mathrm{A}} \mu_{\mathrm{A}^{+}}+\nu_{\mathrm{B}} \mu_{\mathrm{B}^{-}}-\mu_{\mathrm{AB}}=0 .
$$

In general, the chemical potential $\mu_{i}$ is written as the sum of a reference term and a term capturing the deviation from the chosen reference, i.e.,

$$
\mu_{i}=\mu_{i}^{\mathrm{ref}}+R T \ln a_{i}
$$

noting that depending on the component of interest, different standard states $\mu_{i}^{\text {ref }}$ and corresponding activities $a_{i}$ are often used. ${ }^{53}$ Using eqn (10) in eqn (9) and rearranging yields

$$
\exp \left(-\frac{\nu_{\mathrm{A}} \mu_{\mathrm{A}^{+}}^{\mathrm{ref}}+\nu_{\mathrm{B}} \mu_{\mathrm{B}^{-}}^{\mathrm{ref}}-\mu_{\mathrm{AB}}^{\mathrm{ref}}}{R T}\right)=\frac{a_{\mathrm{A}^{+}} a_{\mathrm{B}^{-}}}{a_{\mathrm{AB}}},
$$

where the left-hand side is referred to as the thermodynamic equilibrium constant $K_{\mathrm{a}}$ of the reaction:

$$
K_{\mathrm{a}}=\exp \left(-\frac{\nu_{\mathrm{A}} \mu_{\mathrm{A}^{+}}^{\mathrm{ref}}+\nu_{\mathrm{B}} \mu_{\mathrm{B}^{-}}^{\mathrm{ref}}-\mu_{\mathrm{AB}}^{\mathrm{ref}}}{R T}\right) .
$$

The values of $K_{\mathrm{a}}$ found for different solutions of weak electrolytes can differ by several orders of magnitude and for easier comparison, a logarithmic scale,

$$
\mathrm{p} K_{\mathrm{a}}=-\log _{10}\left(K_{\mathrm{a}}\right)
$$

is introduced.

In the present work, we use correlations of experimental data for the temperature dependence of $\mathrm{p} K_{\mathrm{a}}$ of the systems of interest reported in the literature, and couple them with the thermodynamic modelling carried out with the SAFT-VRE Mie equation of state. 


\subsection{Chemical potential scales}

2.3.1 Ionic species. Two measures of concentration are typically employed when studying electrolyte solutions. The molality $m_{i}$ is defined as

$$
m_{i}=\frac{n_{i}}{\overline{m_{\mathrm{W}}}}
$$

where $n_{i}$ is the number of moles of component $i$ in solution and $\overline{m_{\mathrm{W}}}$ is the mass of pure solvent $\mathrm{W}$. The molarity $c_{i}$ is defined as

$$
c_{i}=\frac{n_{i}}{V}
$$

where $V$ is the volume of the solution. For the chemical potential of a given ionic species $i$ in solution, a Henry-like normalization to infinite dilution is often used. Using a molality scale this leads to

$$
\begin{aligned}
\mu_{i} & =\mu_{i}^{\mathrm{ref} \mathrm{m}}\left(T, p, \mathbf{x}^{*}\right)+R T \ln a_{i}^{* \mathrm{~m}}(T, p, \mathbf{x}) \\
& =\mu_{i}^{\mathrm{ref} \mathrm{m}}\left(T, p, \mathbf{x}^{*}\right)+R T \ln \left(\frac{m_{i}}{m^{0}} \gamma_{i}^{* \mathrm{~m}}(T, p, \mathbf{x})\right),
\end{aligned}
$$

where $\mathbf{x}$ denotes the solution composition, $\mu_{i}^{\text {ref } \mathrm{m}}\left(T, p, \mathbf{x}^{*}\right)$ is the reference chemical potential, $\gamma_{i}^{* \mathrm{~m}}(T, p, \mathbf{x})$ is the activity coefficient in the molality scale, and the unit molality $m^{0}=1 \mathrm{~mol} \mathrm{~kg}^{-1}$ is introduced to render the last term dimensionless. The asterisk ${ }^{*}$ denotes that the normalization is carried out with respect to component $i$ at infinite dilution in the solvent $\mathrm{W}$, with $\mathbf{x}^{*}$ the corresponding reference solution composition. Similarly, in the molarity scale, the chemical potential of the ionic species can be obtained as

$$
\begin{aligned}
\mu_{i} & =\mu_{i}^{\mathrm{ref} \mathrm{c}}\left(T, p, \mathbf{x}^{*}\right)+R T \ln a_{i}^{* \mathrm{c}}(T, p, \mathbf{x}) \\
& =\mu_{i}^{\mathrm{ref} \mathrm{c}}\left(T, p, \mathbf{x}^{*}\right)+R T \ln \left(\frac{c_{i}}{c^{0}} \gamma_{i}^{* \mathrm{c}}(T, p, \mathbf{x})\right),
\end{aligned}
$$

where each of the terms has an analogous meaning as for the molality scale.

Inserting each of the two chemical potential scales presented in eqn (16) and (17) leads to two possible formulations for the dissociation equilibrium condition. The molality-based description yields

$$
K_{\mathrm{a}}^{\mathrm{m}}(T, p)=\exp \left(-\frac{\nu_{\mathrm{A}} \mu_{\mathrm{A}^{+}}^{\mathrm{ref} \mathrm{m}}+\nu_{\mathrm{B}} \mu_{\mathrm{B}^{-}}^{\mathrm{ref} \mathrm{m}}-\mu_{\mathrm{AB}}^{\mathrm{ref} \mathrm{m}}}{R T}\right),
$$

where

$$
K_{\mathrm{a}}^{\mathrm{m}}(T, p)=\frac{m_{\mathrm{A}^{+}} m_{\mathrm{B}^{-}}}{m_{\mathrm{AB}} m^{0}} \frac{\gamma_{\mathrm{A}^{+}}^{* \mathrm{~m}} \gamma_{\mathrm{B}^{-}}^{* \mathrm{~m}}}{\gamma_{\mathrm{AB}}^{* \mathrm{~m}}}
$$

is the equilibrium constant of the dissociation reaction in the molality scale, and the molarity scale leads to

$$
K_{\mathrm{a}}^{\mathrm{c}}(T, p)=\exp \left(-\frac{\nu_{\mathrm{A}} \mu_{\mathrm{A}^{+}}^{\mathrm{ref} \mathrm{c}}+\nu_{\mathrm{B}} \mu_{\mathrm{B}^{-}}^{\mathrm{ref}}-\mu_{\mathrm{AB}}^{\mathrm{ref} \mathrm{c}}}{R T}\right),
$$

where

$$
K_{\mathrm{a}}^{\mathrm{c}}(T, p)=\frac{c_{\mathrm{A}^{+}} c_{\mathrm{B}^{-}} \gamma_{\mathrm{A}^{+}}^{* \mathrm{c}} \gamma_{\mathrm{B}^{-}}^{* \mathrm{c}}}{c_{\mathrm{AB}} c^{0} \quad \gamma_{\mathrm{AB}}^{* \mathrm{c}}}
$$

is the equilibrium constant on the molarity scale. Note that $K_{\mathrm{a}}^{\mathrm{m}}$ and $K_{\mathrm{a}}^{\mathrm{c}}$ depend on both $T$ and $p$ and, by virtue of the normalization employed, also on the choice of solvent W. Here, we consider aqueous solutions at low pressures, so that only the temperature dependence needs to be considered explicitly. The molality scale $m_{i}$ is generally preferred over the molarity $c_{i}$ as no knowledge of the density of the solution is required. Thus, our discussion is limited to properties on the molality scale and we drop the superscript ' $m$ ' hereafter.

2.3.2 Neutral compound. First, we note that at chemical equilibrium, the chemical potential of the neutral compound viewed from the 'true' and 'overall' perspective must be equal:

$$
\mu_{\mathrm{AB}}(T, p, \mathbf{x})=\tilde{\mu}_{\mathrm{AB}}(T, p, \mathbf{x}) .
$$

This equality, also known as Prigogine's theorem, ${ }^{54}$ is derived in Appendix A.

At chemical equilibrium, according to eqn (9) the chemical potential of the neutral compound $\mathrm{AB}$ is

$$
\mu_{\mathrm{AB}}(T, p, \mathbf{x})=\nu_{\mathrm{A}} \mu_{\mathrm{A}^{+}}(T, p, \mathbf{x})+\nu_{\mathrm{B}} \mu_{\mathrm{B}^{-}}(T, p, \mathbf{x}),
$$

so that using the molality scale (eqn (16)) together with Prigogine's theorem yields

$$
\begin{aligned}
\tilde{\mu}_{\mathrm{AB}}(T, p, \mathbf{x})= & \tilde{\mu}_{\mathrm{AB}}^{\mathrm{ref} \mathrm{m}}\left(T, p, \mathbf{x}^{*}\right)+R T \ln \left[\left(\frac{m_{\mathrm{A}^{+}}}{m^{0}}\right)^{\nu_{\mathrm{A}}}\left(\frac{m_{\mathrm{B}^{-}}}{m^{0}}\right)^{\nu_{\mathrm{B}}}\right] \\
& +R T \ln \left[\left(\tilde{\gamma}_{\mathrm{AB}}^{* \mathrm{~m}}(T, p, \mathbf{x})\right)^{\nu_{\mathrm{A}}+\nu_{\mathrm{B}}}\right]
\end{aligned}
$$

where

$$
\tilde{\mu}_{\mathrm{AB}}^{\mathrm{ref} \mathrm{m}}\left(T, p, \mathbf{x}^{*}\right)=\nu_{\mathrm{A}} \mu_{\mathrm{A}^{+}}^{\mathrm{ref} \mathrm{m}}\left(T, p, \mathbf{x}^{*}\right)+\nu_{\mathrm{B}} \mu_{\mathrm{B}^{-}}^{\mathrm{ref} \mathrm{m}}\left(T, p, \mathbf{x}^{*}\right),
$$

and

$$
\tilde{\gamma}_{\mathrm{AB}}^{* \mathrm{~m}}(T, p, \mathbf{x})=\left[\left(\gamma_{\mathrm{A}^{+}}^{* \mathrm{~m}}(T, p, \mathbf{x})\right)^{\nu_{\mathrm{A}}}\left(\gamma_{\mathrm{B}^{-}}^{* \mathrm{~m}}(T, p, \mathbf{x})\right)^{\nu_{\mathrm{B}}}\right]^{\frac{1}{\nu_{\mathrm{A}}+\nu_{\mathrm{B}}}},
$$

is the mean-ionic activity coefficient.

From the definition of $\gamma_{i}^{* \mathrm{~m}}$ given in eqn (16) it is clear that $\tilde{\gamma}_{\mathrm{AB}}^{* \mathrm{~m}}$ depends on the true solution composition. Evaluating this composition when measuring the properties of weak electrolyte solutions is, however, a cumbersome task, so that instead of $\tilde{\gamma}_{\mathrm{AB}}^{* \mathrm{~m}}$ its so-called 'stoichiometric' counterpart $\tilde{\gamma}_{\mathrm{AB}}^{* \mathrm{~m} \text {,stoich }}$ is often used. In principle, $\tilde{\gamma}_{\mathrm{AB}}^{* \mathrm{~m} \text {,stoich }}$ gives the value for the mean-ionic activity coefficient if $\mathrm{AB}$ were dissociated completely at a certain molality $\tilde{m}_{\mathrm{AB}}$. It can be shown ( $c f$. Appendix $\mathrm{B}$ ) that $\tilde{\gamma}_{\mathrm{AB}}^{* \mathrm{~m} \text {,stoich }}$ can be related to the ionic activity coefficients through

$$
\tilde{\gamma}_{\mathrm{AB}}^{* \mathrm{~m}, \text { stoich }}=\left[\frac{1}{\nu_{\mathrm{A}}^{\nu_{\mathrm{A}}} \nu_{\mathrm{B}}^{\nu_{\mathrm{B}}}} \frac{\left(\frac{m_{\mathrm{A}^{+}}}{m^{0}}\right)^{\nu_{\mathrm{A}}}\left(\frac{m_{\mathrm{B}^{-}}}{m^{0}}\right)^{\nu_{\mathrm{B}}}}{\left(\frac{\tilde{m}_{\mathrm{AB}}}{m^{0}}\right)^{\nu_{\mathrm{A}}+\nu_{\mathrm{B}}}}\left(\gamma_{\mathrm{A}^{+}}^{* m}\right)^{\nu_{\mathrm{A}}}\left(\gamma_{\mathrm{B}^{-}}^{* \mathrm{~m}}\right)^{\nu_{\mathrm{B}}}\right]^{\frac{1}{\nu_{\mathrm{A}}+\nu_{\mathrm{B}}}} .
$$

2.3.3 Solvent. As for the neutral compound, at equilibrium the 'true' and 'overall' chemical potentials of the solvent are equal ( $c f$. Appedix A), i.e.,

$$
\mu_{\mathrm{W}}(T, p, \mathbf{x})=\tilde{\mu}_{\mathrm{W}}(T, p, \mathbf{x}) .
$$


The chemical potential of solvent $\mathrm{W}$ is normalized with respect to the pure liquid at the solution's $T$ and $p$,

$$
\mu_{\mathrm{W}}(T, p, \mathbf{x})=\mu_{\mathrm{W}}^{\text {pure liq }}(T, p)+R T \ln a_{\mathrm{W}}(T, p, \mathbf{x}),
$$

and the solvent activity is often rescaled to the osmotic coefficient, which is defined as

$$
\Phi(T, p, \mathbf{x})=-\frac{\ln a_{\mathrm{W}}(T, p, \mathbf{x})}{M_{\mathrm{W}} \sum_{i=1, i \neq \mathrm{W}}^{N} m_{i}}
$$

where $M_{\mathrm{W}}$ is the molar mass of the solvent (in $\mathrm{kg} \mathrm{mol}{ }^{-1}$ ). As evaluating this equation requires knowledge of the true composition of the solution, the stoichiometric osmotic coefficient, defined as,

$$
\Phi^{\text {stoich }}(T, p, \mathbf{x})=-\frac{\ln a_{\mathrm{W}}(T, p, \mathbf{x})}{M_{\mathrm{W}}\left(\nu_{\mathrm{A}}+\nu_{\mathrm{B}}\right) \tilde{m}_{\mathrm{AB}}},
$$

evaluated assuming that the compound $\mathrm{AB}$ is fully dissociated at molality $\tilde{m}_{\mathrm{AB}}$, is used instead.

\subsection{Combined dissociation and phase equilibria}

The calculation of vapour-liquid equilibria (VLE) involving weak electrolytes requires that the condition for chemical equilibrium, $c f$. eqn (9), is satisfied simultaneously with the phase equilibrium condition at fixed $T$ and $p$, i.e.,

$$
\mu_{i}^{\prime}=\mu_{i}^{\prime \prime},
$$

where the primes indicate the two phases, for all components $i$ present in both phases. Due to the low dielectric permittivity of the vapour phase, the ions remain principally in the liquid phase and hence the phase equilibrium condition (eqn (32)) for ionic species $i$ does not need to be solved explicitly. This drastically simplifies the numerical solution of the resulting system of equations. Moreover, it has been shown in previous work $^{46}$ that if condition (32) is also considered explicitly for the ions, the SAFT-VRE Mie modelling would yield very low values for the mole fractions of the ions in the vapour phase.

\section{SAFT-VRE Mie}

\subsection{Equation of state}

The treatment of electrolytes with the SAFT-VRE Mie equation of state (EOS) was presented by Eriksen et al. ${ }^{48}$ The total Helmholtz free energy of the mixture is expressed as a sum of residual terms:

$$
A=A^{\text {Ideal }}+A^{\text {Mono }}+A^{\text {Chain }}+A^{\text {Assoc }}+A^{\text {Ion }}+A^{\text {Born }} .
$$

The first four terms constitute the SAFT-VR Mie EOS presented by Lafitte et al. ${ }^{49}$ and correspond to: the ideal gas free energy $\left(A^{\text {Ideal }}\right)$; the contribution accounting for monomeric spherical segments interacting through Mie potentials of variable range $\left(A^{\mathrm{Mono}}\right)$; the contribution of these monomers bonding to form chain molecules $\left(A^{\text {Chain }}\right)$; and the effect of molecular association through short-ranged directional forces $\left(A^{\text {Assoc }}\right)$. The electrostatic interactions arising from the presence of charged species are treated within the primitive model formalism, where the electrostatic properties of the solvent is described by a uniform dielectric medium. A model for the relative permittivity of the dielectric medium was presented by Schreckenberg et al., ${ }^{46}$ and is adopted here. As the description of the relative permittivity is found to be important for the solutions of weak electrolytes studied here, this model is addressed in more detail in Section 3.4. The Coulombic interactions between charged species in a solvent medium are accounted for in $A^{\text {Ion }}$, using the primitive unrestricted mean spherical approximation (MSA-PM) model of Blum. ${ }^{55,56}$ Instead of an explicit treatment of ion-polar interactions, these are accounted for in $A^{\text {Born }}$, which takes into account the change in free energy associated with charging the ions in a solvent.

We employ two distinct ion size parameters for the two terms: in $A^{\text {Ion }}$, we use the crystal radius, whereas we use larger values of the size parameter for the Born contribution $A^{\text {Born }}$ to effectively account for the solvation-effects of the ions. It has been shown by molecular-dynamics simulation $^{57,58}$ and in a recent generalisation of the Born model $^{59}$ that it would be more accurate to interpret the solvation free-energy change associated with ion-solvent interactions as related to the effect of the ion on the orientation of solvent dipoles in the first and second solvation shells, which leads to a reduced local permittivity rather than to an increase in the ion size. We follow here the original picture of Born as we use a primitive model for the electrostatics, in which the solvent is regarded as a continuum and in order that the models proposed here are consistent with those of our previous work relating to strong electrolytes.

Details of the expressions for each of the Helmholtz energy contributions are not repeated here; the reader is instead referred to the original publications. ${ }^{48,49}$

\subsection{Calculation of activity coefficients with SAFT-VRE Mie}

The activity coefficient is usually defined at a certain state point determined by $T, p$, and $\mathbf{x}$. However, molecular equations of state, written in terms of the Helmholtz free energy, such as SAFT-VRE Mie, are expressed with $T, V$, and $\mathbf{x}$ as the independent variables. As a result the volume $V_{p}$ at a certain pressure of interest $p$ needs to be evaluated from the equation of state. The fugacity coefficients may then be calculated according to

$$
\phi_{i}(T, p, \mathbf{x}) \equiv \phi_{i}\left(T, V_{p}, \mathbf{x}\right)=\frac{n R T}{p V_{p}} \exp \left(\frac{\mu_{i}^{\mathrm{res}}\left(T, V_{p}, \mathbf{x}\right)}{R T}\right),
$$

where $\mu_{i}^{\text {res }}$ is the residual chemical potential obtained as

$$
\mu_{i}^{\mathrm{res}}=\left(\frac{\partial\left(A-A^{\mathrm{Ideal}}\right)}{\partial n_{i}}\right)_{T, V, n_{j \neq i}},
$$

and where $A$ is given by eqn (33). The activity coefficient in the molality scale $(c f$. (16)) can be obtained as

$$
\gamma_{i}^{* \mathrm{~m}}(T, p, \mathbf{x})=\left(\frac{1}{1+M_{\mathrm{W}} \sum_{i=1, i \neq \mathrm{W}}^{N} m_{i}}\right) \frac{\phi_{i}(T, p, \mathbf{x})}{\phi_{i}^{\infty}(T, p)},
$$


where the fugacity coefficients $\phi_{i}$ are in the mole fraction scale, and the term in brackets takes care of the conversion to the molality scale. The fugacity coefficient of component $i$ at infinite dilution in the solvent,

$$
\phi_{i}^{\infty}(T, p)=\lim _{x_{i} \rightarrow 0} \phi_{i}(T, p, \mathbf{x}),
$$

is calculated here by considering a mixture in which the mole fraction of component $i$ is $x_{i}=10^{-10}$.

\subsection{Species models}

3.3.1 Neutral compounds. In the SAFT-VRE Mie EOS, molecules are considered as associating homonuclear chains composed of $m$ spherical segments interacting via Mie intermolecular potentials $u^{\text {Mie }}$ of variable range. The interaction between components $i$ and $j$ in the mixture is given by:

$$
u^{\mathrm{Mie}}=\mathcal{C} \varepsilon_{i j}\left[\left(\frac{\sigma_{i j}}{r_{i j}}\right)^{\lambda_{\mathrm{r}, i j}}-\left(\frac{\sigma_{i j}}{r_{i j}}\right)^{\lambda_{\mathrm{a}, i j}}\right],
$$

with

$$
\mathcal{C}=\frac{\lambda_{\mathrm{r}, i j}}{\lambda_{\mathrm{r}, i j}-\lambda_{\mathrm{a}, i j}}\left(\frac{\lambda_{\mathrm{r}, i j}}{\lambda_{\mathrm{a}, i j}}\right)^{\frac{\lambda_{\mathrm{a}, i j}}{\lambda_{\mathrm{r}, i j}-\lambda_{\mathrm{a}, i j}}},
$$

where $r_{i j}$ is the centre-centre distance between segments $i$ and $j$ of the respective components, $\sigma_{i j}$ is the segment diameter, $\varepsilon_{i j}$ is the depth of the potential, and $\lambda_{\mathrm{a}, i j}$ and $\lambda_{\mathrm{r}, i j}$ are the attractive and repulsive exponents of the intersegment interaction. In the case of associating molecules, the number $N_{\mathrm{ST}, i}$ of site types, the number of sites $n_{y, i}$ of each type $y$, together with the energy $\varepsilon_{i j, a b}^{\mathrm{HB}}$ and the corresponding bonding volume $K_{i j, a b}^{\mathrm{HB}}$ of association between sites must also be specified. All parameters are characterised following the minimisation of an objective function by comparison with experimental data for the system of interest.

3.3.2 Ionic species. In addition to the Mie and association contributions, ionic species possess additional coulombic contributions to the Helmholtz free energy, incorporated via $A^{\text {Ion }}$ and $A^{\text {Born }}$. The ionic contribution is completely defined by the charge of the ion and the parameters introduced earlier; for the Born contribution an additional parameter $\sigma_{i i}^{\text {Born }}$ is introduced. In the present work, all ions $i$ are assumed to be spherical $\left(m_{i}=1\right)$ and are taken to interact via the Lennard-Jones potential $\left(\lambda_{\mathrm{r}, i i}=12\right.$ and $\left.\lambda_{\mathrm{a}, j j}=6\right)$. The segment diameter $\sigma_{i i}$, of a given ion $i$, and the Born diameter $\sigma_{i i}^{\text {Born }}$ are taken from the literature. The like and unlike ion-ion dispersion energy parameters $\varepsilon_{i i}$ and $\varepsilon_{i j}$, respectively, are calculated using a combining rule, ${ }^{48,60}$ based on the work of Hudson and McCoubrey, ${ }^{61}$ which takes into account the polarisability $\alpha_{0}$ and ionisation potential $I$ of the interacting species:

$$
\varepsilon_{i j}=\frac{\left(\lambda_{\mathrm{r}, i j}-3\right)\left(\lambda_{\mathrm{a}, i j}-3\right)}{2 \mathcal{C}\left(\lambda_{\mathrm{r}, i j}-\lambda_{\mathrm{a}, i j}\right)} \frac{\alpha_{0, i} \alpha_{0, j}}{\left(4 \pi \varepsilon_{0}\right)^{2} \sigma_{i j}^{6}} \frac{I_{i} I_{j}}{I_{i}+I_{j}},
$$

where $\varepsilon_{0}$ is the permittivity of vacuum. A number of the ionic species studied here are modelled including unlike association interactions with other species; self-association of ionic species is however not considered.

3.3.3 Unlike interactions. The interactions between a given pair of unlike components $i$ and $j$ can be estimated through appropriate combining rules, provided that the parameters of the individual segments in the models have been characterised. In the present work, the unlike segment diameter is always obtained as a simple arithmetic mean, ${ }^{62}$

$$
\sigma_{i j}=\frac{\sigma_{i i}+\sigma_{j j}}{2} \text {. }
$$

Furthermore, the combining rule derived from applying the geometric-mean criterion to the van der Waals attractive energy ${ }^{49,50}$ is applied throughout the present work to obtain all of the unlike attractive and repulsive Mie exponents:

$$
\lambda_{z, i j}=3+\sqrt{\left(\lambda_{z, i i}-3\right)\left(\lambda_{z, j j}-3\right)}, \quad z \in\{a, r\} .
$$

In the case of interactions between two neutral compounds $i$ and $j$, the unlike dispersion energy can be obtained using an augmented geometric mean which accounts for the size asymmetry of the segments, ${ }^{62}$

$$
\varepsilon_{i j}=\frac{\sqrt{\sigma_{i i}^{3} \sigma_{j j}^{3}}}{\sigma_{i j}{ }^{3}} \sqrt{\varepsilon_{i i} \varepsilon_{j j}} .
$$

The value obtained from this combining rule is, however, typically used only as an initial estimate to guide further refinement of this parameter with respect to experimental data. In the case of interactions between unlike ions $i$ and $j$, the unlike dispersion energy parameter is always obtained from the Hudson-McCoubrey combining rule, $c f$. eqn (40).

Combining rules can also be used to determine the parameters of the association interaction between an unlike pair of molecules associating via site $a$ on molecule $i$ and site $b$ on molecule $j$. A simple geometric combining rule is used for the unlike association energy, ${ }^{51,63}$

$$
\varepsilon_{i j, a b}^{\mathrm{HB}}=\sqrt{\varepsilon_{i i, a a}^{\mathrm{HB}} \varepsilon_{j j, b b}^{\mathrm{HB}}},
$$

and the unlike bonding volume is obtained by an arithmetic combining rule averaging the volumes of the like interactions: ${ }^{51,63}$

$$
K_{i j, a b}^{\mathrm{HB}}=\left(\frac{\sqrt[3]{K_{i i, a a}^{\mathrm{HB}}}+\sqrt[3]{K_{j j, b b}^{\mathrm{HB}}}}{2}\right)^{3}
$$

However, as for the unlike dispersion energy, the unlike association parameters resulting from the expressions above are often used only as initial estimates for further refinement of the model with respect to experimental data.

\subsection{Relative permittivity model}

The relative permittivity $D$ is a key property of electrolyte systems. In the present work, it is required for the evaluation of the $A^{\text {Ion }}$ and $A^{\text {Born }}$ contributions of the Helmholtz free energy. In addition to the dependence of $D$ on the state conditions, the so-called dielectric decrement, i.e. the decrease in the relative 
permittivity with increasing concentration of the ions, is wellknown. By using an electrostatic field-theory ${ }^{64,65}$ and Monte Carlo simulations ${ }^{66}$ the origin of the dielectric decrement has recently been identified to be the saturation of solvent dipoles in close proximity to an ion. In the context of our work it is also of interest to highlight the work of Maribo-Mogensen et al. ${ }^{67}$ who have proposed a model for the relative permittivity over wide ranges of temperature, pressure and composition to be used in equation of state models, which can account for the decrement in the values of $D$ as the ion concentration increases. Moreover, a further consideration arises from the fact that the relative permittivity must be formulated in a way such that the resulting equation of state is thermodynamically consistent. ${ }^{46}$

A simple model for the relative permittivity that fulfills the requirements has been presented: ${ }^{46}$ it accounts (to some extent) for the dielectric decrement as the ion concentration increases, and satisfies the Gibbs-Duhem thermodynamic relation. In our model the relative permittivity $D$ of the solution is given by

$$
D=1+\rho_{\text {solv }} d,
$$

where $d$ is a solvent-dependent parameter given by

$$
d=d_{\mathrm{V}}\left(\frac{d_{\mathrm{T}}}{T}-1\right)
$$

and where it is important to note that since the density of the solvent in the mixture $\rho_{\text {solv }}$ appears in eqn (46), the model intrinsically accounts for the dielectric decrement effect. In case of mixed solvents, the following combining rules are applied: ${ }^{46}$

$$
d\left(\hat{x}_{i}\right)=\sum_{i=1}^{N_{\text {solv }}} \sum_{j=1}^{N_{\text {solv }}} \hat{x}_{i} \hat{x}_{j} d_{i j}
$$

where the hat is used to indicate true ion-free mole fractions, i.e.,

$$
\hat{x}_{i}=\frac{n_{i}}{\sum_{j=1, j \neq \text { ion }}^{N} n_{j}},
$$

where the sum runs over all non-charged species, and the parameter $d_{i j}$ is given by

$$
d_{i j}=\frac{d_{i i}+d_{j j}}{2} .
$$

In these systems, all neutral molecular species must be treated as 'additional solvents', especially at high concentrations of such species. Thus, they need to be assigned $d_{\mathrm{V}}$ and $d_{\mathrm{T}}$ parameters in the model, as they would otherwise contribute an unphysical dielectric decrement effect akin to that of the ions. This is especially important when modelling aqueous solutions of nitric acid, for which the entire concentration range from pure water to pure nitric acid is studied. At high concentrations of nitric acid in water, the equilibrium is such that almost all of the nitric acid remains in its molecular (neutral) form, $c f$. Section 5.3.1. The relative permittivity of undissociated nitric acid is needed to model this region. Unfortunately, to the best of our knowledge, no experimental data on the relative permittivity of pure nitric acid are available. We propose the use of an analogy: nitric acid and methanol have similar molar densities and dipole moments of similar order of magnitude. In the model given by eqn (46), the parameter $d$ provides a measure of 'polarity per volume'. Thus, if two substances have the same molar density and a similar polarity, they can be expected to be characterised by a similar $d$ parameter. We therefore adopt the $d_{\mathrm{V}}$ and $d_{\mathrm{T}}$ parameters for methanol presented in earlier work. ${ }^{46}$ and use them to obtain an estimate of the relative permittivity of nitric acid. In the carbonic acid system, carbon dioxide is the only additional molecular species, for which the parameters $d_{\mathrm{V}}$ and $d_{\mathrm{T}}$ have been provided. ${ }^{46}$ In the solutions of sulphuric acid, water is the only molecular species.

\subsection{Parameter estimation strategy}

In the present work, we develop new SAFT-VRE Mie models for the ions needed to model aqueous solutions of sulphuric, nitric, and carbonic acid, as well as a model for molecular nitric acid. Models for water and the hydronium ion are taken from previous work. ${ }^{48,51}$ All parameters of the model of pure nitric acid are determined by comparison to experimental vapour-liquid equilibrium data. As outlined above, in order to model the mixtures of interest, the only parameters that are estimated from the experimental data are the unlike energy parameters $\varepsilon_{i j}$ (where either $i$ or $j$, or both, is a neutral compound or solvent) and the association parameters $\varepsilon_{i j}^{\mathrm{HB}}$ and $K_{i j}^{\mathrm{HB}}$ (where $i$ and $j$ may be a neutral or ionic species). These parameters are obtained by minimising an objective function $F_{\text {obj }}$, containing the sum of squares of the relative deviations between experimental data and calculated values of several objectives $Z_{k}$ :

$$
\min F_{\text {obj }}=\sum_{k=1}^{N_{\text {Prop }}} \frac{1}{N_{p, k}} \sum_{l=1}^{N_{p, k}}\left(\frac{Z_{k, l}^{\text {exp }}-Z_{k, l}^{\text {calc }}}{Z_{k, l}^{\exp }}\right)^{2}
$$

where $N_{\text {Prop }}$ is the number of properties considered, $N_{p, k}$ is the number of evaluated state points for property $Z_{k}$, and $Z_{k, l}^{\exp }$ and $Z_{k, l}^{\text {calc }}$ denote the experimental and calculated values of property $Z_{k}$ at state point $l$. Details of the parameter estimation procedure, i.e., the choice of properties and parameters to adjust for each of the weak electrolytes considered, are given in the corresponding section.

The parameters of the SAFT-VRE Mie models developed in the present work are compiled in Tables 1-3, and the ionisation potentials and polarisabilities used for determining the ion-ion dispersion energy parameters are compiled in Table 4.

\section{Sulphuric acid}

Sulphuric acid $\left(\mathrm{H}_{2} \mathrm{SO}_{4}\right)$ is a highly polar substance, which is in the liquid state at ambient conditions. It undergoes autoprotolysis and is highly hygroscopic. In aqueous solution, sulphuric acid is generally regarded as a 'strong' acid due to its $2: 1$ stoichiometry, forming the bisulfate $\left(\mathrm{HSO}_{4}{ }^{-}\right)$and sulfate $\left(\mathrm{SO}_{4}{ }^{2-}\right)$ ions. Although it can also be considered a weak electrolyte, in that the dissociation of the second proton is typically incomplete, except at very high dilution. Nevertheless, aqueous solutions of sulphuric acid are highly acidic and are used as oxidizing and dehydrating agents. 
Table 1 SAFT-VRE Mie model parameters for the species present in aqueous solutions of sulphuric acid, nitric acid, and carbonic acid. The models for $\mathrm{H}_{2} \mathrm{O}, \mathrm{H}_{3} \mathrm{O}^{+}$, and $\mathrm{CO}_{2}$ are taken from previous work (ref. 48, 51 and 68 respectively). All other models are developed in this work. For a species $i, m_{i}$ is the chain length, $\sigma_{i i}$ the segment diameter, $\sigma_{i i}^{\text {Born }}$ is the Born diameter (applicable to ions only), $\lambda_{\mathrm{r}, i i}$ and $\lambda_{\mathrm{a}, i i}$ are the repulsive and attractive exponents of the Mie potential, respectively, $\varepsilon_{i i}$ is the dispersion energy, $n_{\mathrm{H}, i}$ and $n_{\mathrm{e}, i}$ are the numbers of ' $\mathrm{H}$ ' (hydrogen-bond donor) and 'e' (hydrogen-bond acceptor) type association sites, respectively, $\varepsilon_{i i, a b}^{\mathrm{HB}}$ is the association strength of the interaction of two sites $a$ and $b$, and $K_{i i, a b}^{\mathrm{HB}}$ is the corresponding bonding volume

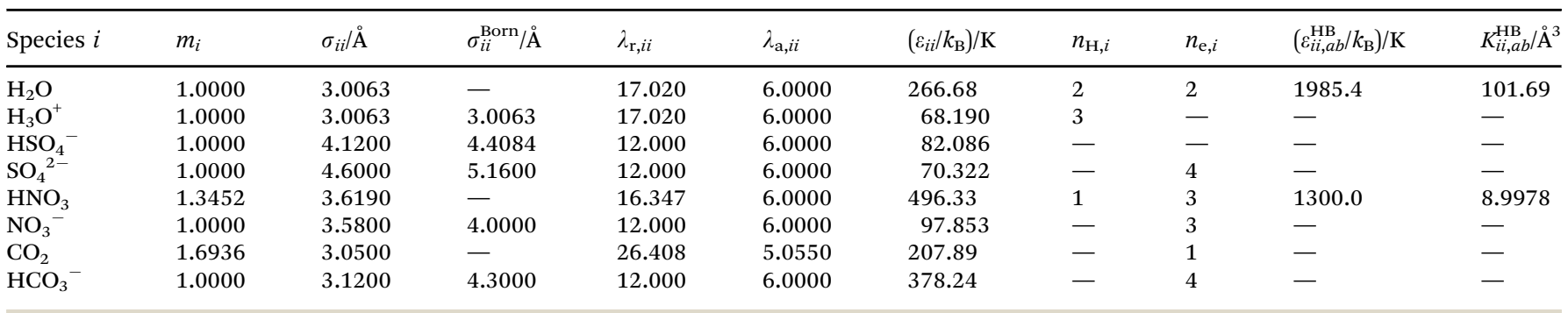

Table 2 SAFT-VRE Mie unlike-interaction parameters for the species present in aqueous solutions of sulphuric acid, nitric acid, and carbonic acid. The unlike-interaction parameters $\sigma_{i j}, \lambda_{r, i j}$, and $\lambda_{a, i j}$ are omitted from this table as they are obtained with combining rules, eqn (41) and (42), respectively. The interaction parameters for $\mathrm{H}_{2} \mathrm{O}-\mathrm{H}_{3} \mathrm{O}^{+}$and $\mathrm{H}_{2} \mathrm{O}-\mathrm{CO}_{2}$ are taken from ref. 48 and 68 , respectively. All other unlike interaction parameters are developed in this work. All unlike ion-ion dispersion energies are calculated using the Hudson-McCoubrey rule. ${ }^{61}$ The procedures for the determination of the remaining parameters are detailed in the text

\begin{tabular}{|c|c|c|c|c|c|c|}
\hline \multicolumn{2}{|l|}{$\underline{\text { Species }}$} & \multicolumn{2}{|c|}{ Site } & \multirow[b]{2}{*}{$\left(\varepsilon_{i j, a b}^{\mathrm{HB}} / k_{\mathrm{B}}\right) / \mathrm{K}$} & \multirow[b]{2}{*}{$K_{i j, a b}^{\mathrm{HB}} / \AA^{3}$} & \multirow[b]{2}{*}{$\left(\varepsilon_{i j} / k_{\mathrm{B}}\right) / \mathrm{K}$} \\
\hline$i$ & $j$ & $i, a$ & $j, b$ & & & \\
\hline $\mathrm{H}_{2} \mathrm{O}$ & $\mathrm{H}_{3} \mathrm{O}^{+}$ & $\mathrm{e}$ & $\mathrm{H}$ & 1985.4 & 101.69 & 391.04 \\
\hline $\mathrm{H}_{2} \mathrm{O}$ & $\mathrm{HSO}_{4}{ }^{-}$ & - & - & - & - & 142.57 \\
\hline $\mathrm{H}_{2} \mathrm{O}$ & $\mathrm{SO}_{4}{ }^{2-}$ & - & - & - & - & 128.03 \\
\hline $\mathrm{HSO}_{4}{ }^{-}$ & $\mathrm{H}_{3} \mathrm{O}^{+}$ & - & - & - & - & 60.476 \\
\hline $\mathrm{HSO}_{4}^{-}$ & $\mathrm{SO}_{4}{ }^{2-}$ & - & - & - & - & 75.239 \\
\hline $\mathrm{H}_{3} \mathrm{O}^{+}$ & $\mathrm{SO}_{4}{ }^{2-}$ & $\mathrm{H}$ & e & 2266.0 & 43.700 & 53.609 \\
\hline $\mathrm{H}_{2} \mathrm{O}$ & $\mathrm{HNO}_{3}$ & $\mathrm{H}$ & $\mathrm{e}$ & 2900.0 & 38.401 & 270.00 \\
\hline $\mathrm{H}_{2} \mathrm{O}$ & $\mathrm{HNO}_{3}$ & e & $\mathrm{H}$ & 1606.6 & 38.401 & 270.00 \\
\hline $\mathrm{H}_{2} \mathrm{O}$ & $\mathrm{NO}_{3}{ }^{-}$ & $\mathrm{H}$ & e & 2350.0 & 97.014 & 161.55 \\
\hline $\mathrm{HNO}_{3}$ & $\mathrm{H}_{3} \mathrm{O}^{+}$ & - & - & - & - & 181.61 \\
\hline $\mathrm{HNO}_{3}$ & $\mathrm{NO}_{3}^{-}$ & - & - & - & - & 220.37 \\
\hline $\mathrm{H}_{3} \mathrm{O}^{+}$ & $\mathrm{NO}_{3}^{-}$ & $\mathrm{H}$ & $\mathrm{e}$ & 2900.0 & 38.401 & 61.788 \\
\hline $\mathrm{H}_{2} \mathrm{O}$ & $\mathrm{CO}_{2}$ & $\mathrm{H}$ & $\mathrm{e}$ & 1398.1 & 91.419 & 226.38 \\
\hline $\mathrm{H}_{2} \mathrm{O}$ & $\mathrm{HCO}_{3}{ }^{-}$ & $\mathrm{H}$ & $\mathrm{e}$ & 1398.1 & 91.419 & 317.43 \\
\hline $\mathrm{CO}_{2}$ & $\mathrm{H}_{3} \mathrm{O}^{+}$ & - & - & - & - & 189.86 \\
\hline $\mathrm{CO}_{2}$ & $\mathrm{HCO}_{3}{ }^{-}$ & - & - & - & - & 371.59 \\
\hline $\mathrm{H}_{3} \mathrm{O}^{+}$ & $\mathrm{HCO}_{3}{ }^{-}$ & $\mathrm{H}$ & e & 1398.1 & 91.419 & 130.28 \\
\hline
\end{tabular}

Table 3 Parameters for the dielectric constant correlation, taken from ref. 46

\begin{tabular}{lcl}
\hline Species & $d_{\mathrm{V}} / \mathrm{dm}^{3} \mathrm{~mol}^{-1}$ & $d_{\mathrm{T}} / \mathrm{K}$ \\
\hline $\mathrm{H}_{2} \mathrm{O}$ & 0.3777 & 1403.0 \\
$\mathrm{HNO}_{3}$ & 0.5484 & 1011.0 \\
$\mathrm{CO}_{2}$ & -0.0250 & 0
\end{tabular}

\subsection{Dissociation equilibrium}

In aqueous solution, sulphuric acid undergoes two sequential dissociation steps, ${ }^{74}$ both of which entail a proton-transfer reaction with water:

$$
\mathrm{H}_{2} \mathrm{SO}_{4}+\mathrm{H}_{2} \mathrm{O} \stackrel{K_{\mathrm{al}}}{\rightleftharpoons} \mathrm{H}_{3} \mathrm{O}^{+}+\mathrm{HSO}_{4}^{-}
$$

Table 4 Values for the polarisability and electron affinity of the ions relevant to this work. Data for $\mathrm{HSO}_{4}{ }^{-}$and $\mathrm{SO}_{4}{ }^{2-}$ are taken from ref. 69-71, data for $\mathrm{NO}_{3}{ }^{-}$are taken from ref. 69 and 72 , and data for $\mathrm{CO}_{2}$ and $\mathrm{HCO}_{3}{ }^{-}$are taken from ref. 69 and 73

\begin{tabular}{llc}
\hline Species & $\alpha_{0} /\left(10^{-24} \mathrm{~cm}^{3}\right)$ & \multicolumn{1}{c}{} \\
\hline $\mathrm{HSO}_{4}{ }^{-}$ & 5.0890 & 4.7500 \\
$\mathrm{SO}_{4}{ }^{2-}$ & 6.3270 & 5.1000 \\
$\mathrm{NO}_{3}{ }^{-}$ & 4.4800 & 3.1450 \\
$\mathrm{CO}_{2}{ }^{-}$ & 2.9100 & 13.780 \\
$\mathrm{HCO}_{3}{ }^{-}$ & 5.3900 & 3.6800
\end{tabular}

and

$$
\mathrm{HSO}_{4}^{-}+\mathrm{H}_{2} \mathrm{O} \stackrel{K_{\mathrm{a} 2}}{\rightleftharpoons} \mathrm{H}_{3} \mathrm{O}^{+}+\mathrm{SO}_{4}{ }^{2-} \text {. }
$$

The thermodynamic equilibrium constants $K_{\mathrm{a} 1}$ and $K_{\mathrm{a} 2}$ corresponding to the first and second dissociation steps, respectively, characterise the thermodynamic equilibrium for these reactions. Using the molality scale, they are given by (cf. eqn (19))

$$
K_{\mathrm{al}}(T)=\frac{m_{\mathrm{H}_{3} \mathrm{O}^{+}} m_{\mathrm{HSO}^{-}} \gamma_{\mathrm{H}_{3} \mathrm{O}^{+}} \gamma_{\mathrm{HSO}_{4}}^{* m}}{m_{\mathrm{H}_{2} \mathrm{SO}_{4}} m^{0}}
$$

and

$$
K_{\mathrm{a} 2}(T)=\frac{m_{\mathrm{H}_{3} \mathrm{O}^{+}} m_{\mathrm{SO}_{4}{ }^{2-}}}{m_{\mathrm{HSO}_{4}-} m^{0}} \frac{\gamma_{\mathrm{H}_{3} \mathrm{O}^{+}}^{* \mathrm{~m}} \gamma_{\mathrm{SO}_{4} 2^{-}}^{* m}}{\gamma_{\mathrm{HSO}_{4}}^{* \mathrm{~m}}}
$$

There is consensus in the literature that $K_{\mathrm{a} 1}(T) \rightarrow \infty$, so that the first dissociation step is essentially complete, except at very high acid concentrations $\tilde{c}_{\mathrm{H}_{2} \mathrm{SO}_{4}}>14 \mathrm{~mol} \mathrm{l}{ }^{-1} \cdot{ }^{74-76}$ By contrast, the second dissociation step is comparatively weak, with $K_{\mathrm{a} 2}(298 \mathrm{~K})=0.0105,{ }^{77}$ i.e., $\mathrm{p} K_{\mathrm{a} 2} \approx 1.98$. A variety of reaction mechanisms have been suggested, with investigators proposing a range of intermediate proton transfer steps, hydrogen-bonded ion-solvent complexes, and ion-association equilibria. ${ }^{78-81}$ For the purpose of equation-of-state modelling, the intermediate reaction steps need not be explicitly considered; nevertheless, these propositions can provide valuable insight into association interactions that may be incorporated in a SAFT-type modelling (cf. Section 4.2).

Within the composition range $\left(\tilde{m} \leq 10 \mathrm{~mol} \mathrm{~kg}^{-1}\right)$ where the SAFT-VRE Mie EOS is applicable to electrolyte solutions, ${ }^{46}$ the first dissociation step of sulphuric acid can be considered to be 
complete, and therefore the reaction equilibrium for the first dissociation step does not need to be taken into account explicitly. The second (weak) dissociation step is solved by imposing the thermodynamic equilibrium constant $K_{\mathrm{a} 2}$ at the temperature of interest in the SAFT-VRE Mie calculations.

Significant research effort has been expended into determining the second thermodynamic equilibrium constant of sulphuric acid. Dickson et $a .^{82}$ employed electrochemical-cell measurements to determine $K_{\mathrm{a} 2}$ and proposed an empirical equation applicable in the temperature range 283-523 K. Holmes and Mesmer $^{83}$ used their correlation together with new and previously published $^{84}$ isopiestic data to propose a new correlation for $K_{\mathrm{a} 2}$. A thorough examination of the thermodynamic data (osmotic coefficient, vapour pressure, electromotive force, enthalpy of dilution, heat capacity, and degree of dissociation) available at the time was performed by Clegg et al., ${ }^{77}$ on the basis of which a value of 0.0105 was recommended for $K_{\mathrm{a} 2}$ at $298 \mathrm{~K}$. Using this benchmark, Clegg et al. evaluated various correlations for $K_{\mathrm{a} 2}$ based on their reproduction of critically assessed experimental data in the ranges of $\tilde{m}_{\mathrm{H}_{2} \mathrm{SO}_{4}}=0-6.1 \mathrm{~mol} \mathrm{~kg}^{-1}$ and $T=273-328 \mathrm{~K}$ using an extended Pitzer model. They recommended a truncated version of Dickson's equation, given as

$$
\begin{aligned}
\log _{10} K_{\mathrm{a} 2}= & 562.69486-102.5154 \ln (T / \mathrm{K}) \\
& -1.117033 \times 10^{-4}\left((T / \mathrm{K})^{2}\right) \\
& +0.2477538(T / \mathrm{K})-\frac{13273.75}{(T / \mathrm{K})} .
\end{aligned}
$$

More recently, Sippola ${ }^{85,86}$ examined six equations for the thermodynamic equilibrium constant, including those of Pitzer et al., ${ }^{84}$ Matsushima and Okuwaki, ${ }^{87}$ Dickson et al. ${ }^{82}$ Hovey and Hepler, ${ }^{88}$ Clegg et al., ${ }^{77}$ and Knopf et al. ${ }^{89}$ The equations of Matsushima, Dickson, Hovey, and Clegg et al. were found to give the most reliable values for $K_{\mathrm{a} 2}$ overall, although the equation of Knopf et al. was found to be more suitable for use at high temperatures. Sippola concludes that the choice of correlation ultimately depends on the temperature range of the intended application. For the purpose of this work, we choose to apply the correlation given by eqn (56). This equation has been developed so as to give an accurate $K_{\mathrm{a} 2}$ value at $298 \mathrm{~K}$, which is the temperature at which most of the thermodynamic data are available for sulphuric acid.

\subsection{Association scheme}

The appropriate speciation behaviour in this complex system is still the subject of much debate. Edward and Wang ${ }^{78}$ measured the ultraviolet absorption of aqueous sulphuric acid solutions and used the Raman spectrum data of Young et al. ${ }^{90}$ to propose the existence of sulfate-hydronium ion pairs $\left[\mathrm{H}_{3} \mathrm{O}^{+} \cdot \mathrm{SO}_{4}{ }^{2-}\right]$ and ion triplets $\left[\mathrm{H}_{3} \mathrm{O}^{+} \cdot \mathrm{SO}_{4}{ }^{2-} \cdot \mathrm{H}_{3} \mathrm{O}^{+}\right]$, predominantly at high concentrations of $\tilde{c}_{\mathrm{H}_{2} \mathrm{SO}_{4}}>7 \mathrm{~mol} \mathrm{l}{ }^{-1}$. The authors argue that these ion pairs are the result of abundant hydrogen bonding between the hydronium ions and water molecules, which limits the amount of water available to hydrate other ions, thus promoting ionassociation of the unhydrated sulfate ions. A similar conclusion was reached by Irish and Chen, ${ }^{81}$ who examined Raman spectra of aqueous sulphuric acid and suggested that the second dissociation step of sulphuric acid is driven by a proton transfer equilibrium between the hydrated bisulfate ion $\left(\mathrm{H}_{2} \mathrm{O}\right) \mathrm{HSO}_{4}{ }^{-}$ and the sulfate-hydronium ion-pair $\left[\mathrm{H}_{3} \mathrm{O}^{+} \cdot \mathrm{SO}_{4}{ }^{2-}\right]$, i.e.,

$$
\left(\mathrm{H}_{2} \mathrm{O}\right) \mathrm{HSO}_{4}{ }^{-} \rightleftharpoons\left[\mathrm{H}_{3} \mathrm{O}^{+} \cdot \mathrm{SO}_{4}{ }^{2-}\right] \text {. }
$$

In subsequent work, Chen and Irish ${ }^{79}$ extended this argument by proposing the formation of the bisulfate-hydronium ion pair $\left[\mathrm{H}_{3} \mathrm{O}^{+} \cdot \mathrm{HSO}_{4}{ }^{-}\right]$through a further proton-transfer reaction equilibrium:

$$
\left[\mathrm{H}_{3} \mathrm{O}^{+} \cdot \mathrm{HSO}_{4}{ }^{-}\right]+\mathrm{SO}_{4}{ }^{2-} \rightleftharpoons \mathrm{HSO}_{4}{ }^{-}+\left[\mathrm{H}_{3} \mathrm{O}^{+} \cdot \mathrm{SO}_{4}{ }^{2-}\right] \text {. }
$$

Cox et $a l .{ }^{80}$ also analysed Raman spectra and put forward a dissociation sequence for sulphuric acid involving three equilibrium steps. In this scheme, the fist acid dissociation reaction given by eqn (52) is replaced by two equilibrium steps: first the formation of a hydrated bisulfate-hydronium ion pair,

$$
\mathrm{H}_{2} \mathrm{SO}_{4}+\mathrm{H}_{2} \mathrm{O} \rightleftharpoons\left[\left(\mathrm{H}_{2} \mathrm{O}\right) \mathrm{HSO}_{4}{ }^{-} \cdot \mathrm{H}_{3} \mathrm{O}^{+}\right],
$$

followed by equilibrium of this ion pair with the free bisulfate and hydronium ions. The existence of the $\left[\left(\mathrm{H}_{2} \mathrm{O}\right) \mathrm{HSO}_{4}{ }^{-} \cdot \mathrm{H}_{3} \mathrm{O}^{+}\right]$ ion pair at high concentrations was first proposed by Irish and Chen $^{81}$ as an alternative interpretation of the $\left[\mathrm{H}_{3} \mathrm{O}^{+} \cdot \mathrm{H}_{2} \mathrm{SO}_{4}\right]$ species suggested by Wyatt. ${ }^{91}$ Cox et al., ${ }^{80}$ however, argued that the hydronium-bisulfate ion-pair is formed in the initial dissociation step and is present at all acid concentrations, including dilute solutions.

Admittedly, the presence of these various ion pairs has not been verified and the true composition of the aqueous sulphuric acid solution is still under debate. ${ }^{92}$ In addition, the hydration state of the sulfate and bisulfate ions also remains unresolved. Both ions would be expected to form multiple hydrogen bonds with water and studies have suggested that both sulfate and bisulfate ions form complex hydrogen-bonded clusters with water in solution. Yacovitch et al. ${ }^{93}$ studied the hydration of the bisulfate ion using infrared spectroscopy, observing $\mathrm{HSO}_{4}{ }^{-}\left(\mathrm{H}_{2} \mathrm{O}\right)_{n}$ clusters involving up to 16 water molecules with inter-water bonding within the clusters, starting at $n \geq 2$. In a study using photoelectron spectroscopy to study the hydration of the sulfate ion, Wang et $a .^{94}$ identified $\mathrm{SO}_{4}{ }^{2-}\left(\mathrm{H}_{2} \mathrm{O}\right)_{n}$ clusters involving up to 10 water molecules. A minimum of three water molecules were found necessary to stabilise the $\mathrm{SO}_{4}{ }^{2-}$ ion, and inter-water bonding within the cluster was proposed to start at $n \geq 5$.

Despite doubt over the longevity of the hydration clusters and inconclusive evidence of ion association, hydrogen bonding of $\mathrm{HSO}_{4}{ }^{-}$and $\mathrm{SO}_{4}{ }^{2-}$ with water and with the hydronium ion are considered in our SAFT-VRE Mie modelling approach, the latter interaction intended to mimic the ion pairing effects. Several different association schemes are tested here. When studying the sensitivity of the thermodynamic properties with respect to the association parameters, we observe that only one of the many possible association interactions has a noticeable impact on the resulting agreement between our model and the experimental data: the association between $\mathrm{SO}_{4}{ }^{2-}$ and $\mathrm{H}_{3} \mathrm{O}^{+}$. Thus, only this 
association is introduced in the final SAFT-VRE Mie model for aqueous sulphuric acid. Four 'e' type sites are placed on $\mathrm{SO}_{4}{ }^{2-}$ which only interact with the ' $\mathrm{H}$ ' type sites on $\mathrm{H}_{3} \mathrm{O}^{+}$.

\subsection{Model development}

4.3.1 Objectives. Two target properties are considered in the adjustment of the model parameters ( $c f$. eqn (51)): the degree of dissociation of the bisulfate ion $\alpha_{\mathrm{HSO}_{4}^{-}}$, defined as

$$
\alpha_{\mathrm{HSO}_{4}^{-}}=\frac{m_{\mathrm{SO}_{4}^{2-}}}{m_{\mathrm{HSO}_{4}{ }^{-}}+m_{\mathrm{SO}_{4}{ }^{2-}}}=\frac{m_{\mathrm{SO}_{4}^{2-}}}{\tilde{m}_{\mathrm{H}_{2} \mathrm{SO}_{4}}},
$$

and the water activity $a_{\mathrm{H}_{2} \mathrm{O}}$ (eqn (29)), both at $298.15 \mathrm{~K}$ and 1 bar. The experimental data for the degree of dissociation ${ }^{78,79,95}$ are considered up to $\tilde{c}_{\mathrm{H}_{2} \mathrm{SO}_{4}} \approx 5 \mathrm{~mol} \mathrm{l} \mathrm{l}^{-1}$ and the water activity data ${ }^{96-98}$ are considered up to $\tilde{m}_{\mathrm{H}_{2} \mathrm{SO}_{4}} \approx 3 \mathrm{~mol} \mathrm{~kg}^{-1}$ in the parameter determination step.

4.3.2 Like parameters. The ionic diameters $\sigma_{i i}$ assigned to the ions must reflect the size and charge density of the species relative to each other. The more negative charge and hence stronger repulsions in the $\mathrm{SO}_{4}{ }^{2-}$ ion lead to a larger diameter compared to $\mathrm{HSO}_{4}{ }^{-}$, in which the gain of a proton leads to more tightly held electrons. The sizes of these ions are reported in the literature, most commonly as the radius of the ions in a crystal lattice. The thermochemical ionic sizes given by Krestov $^{99}$ are selected for both ions in this work; using a single internally consistent source for these parameters also satisfies the requirement of relative size mentioned above.

The Born diameter for the $\mathrm{SO}_{4}{ }^{2-}$ model is obtained from the extensive study of Babu and $\mathrm{Lim}^{57}$ in which the Born cavity size of the ions was identified using molecular-dynamics simulations. The bisulfate ion was not considered in their study, therefore the Born cavity diameter of $\mathrm{HSO}_{4}{ }^{-}$is determined by implementing the method proposed by Rashin and Honig, ${ }^{100}$ namely that a reasonable measure of the cavity size of anions can be obtained by applying a $7 \%$ increase to the ionic diameters of the ions. The diameter that Babu and $\mathrm{Lim}^{57}$ recommend for the sulfate ion is $12 \%$ larger than the crystal ionic diameter assigned to this ion. This is comparable to the $7 \%$ increase recommended by Rashin and Honig, hence the two sources are considered compatible.

The dispersion energy $\varepsilon_{i i}$ corresponding to the attractive interaction between two ions of the same type $i$ is determined by applying the ion-ion combining rule given in eqn (40). The polarisabilities of $\mathrm{HSO}_{4}{ }^{-}$and $\mathrm{SO}_{4}{ }^{2-}$ are obtained from Pyper et $a{ }^{69}{ }^{69}$ and Hou et al. ${ }^{70}$ respectively, and the ionisation potentials of both ions are obtained from Wang et al. $;^{71}$ these values are collected in Table 4 .

4.3.3 Unlike parameters. The parameters $\lambda_{\mathrm{a}, i j}, \lambda_{\mathrm{r}, i j}$, and $\sigma_{i j}$ between any two unlike species, as well as the dispersion energy parameter $\varepsilon_{i j}$ between any two ions are determined from combining rules as detailed in Section 3.3.3. The remaining interaction parameters that need to be determined are the dispersion energies $\varepsilon_{\mathrm{H}_{2} \mathrm{O}, \mathrm{HSO}_{4}{ }^{-}}$and $\varepsilon_{\mathrm{H}_{2} \mathrm{O}, \mathrm{SO}_{4}{ }^{2-}}$ as well as the parameters of the association interaction between $\mathrm{SO}_{4}{ }^{2-}$ and $\mathrm{H}_{3} \mathrm{O}^{+}$.

When estimating these parameters by comparison to experimental data, it is found that the degree of dissociation and water activity rather insensitive to the unlike energy parameters $\varepsilon_{\mathrm{H}_{2} \mathrm{O}, \mathrm{SO}_{4}{ }^{2-}}$ and $\varepsilon_{\mathrm{H}_{2} \mathrm{O}, \mathrm{HSO}_{4}{ }^{-}}$, and the values obtained from the combining rule, $c f$. eqn (43), are used directly. By contrast, the association parameters between $\mathrm{SO}_{4}{ }^{2-}$ and $\mathrm{H}_{3} \mathrm{O}^{+}$have a great influence on both objectives. Optimizing the description of the experimental data by varying the two association parameters $\varepsilon_{\mathrm{H}_{3} \mathrm{O}^{+}, \mathrm{SO}_{4}{ }^{2-}}^{\mathrm{HB}}$ and $K_{\mathrm{H}_{3} \mathrm{O}^{+}, \mathrm{SO}_{4}{ }^{2-}}^{\mathrm{HB}}$ leads to parameters indicating a strong association interaction, $c f$. Table 2. This supports the hypothesis of strongly associated $\left[\mathrm{H}_{3} \mathrm{O}^{+} \cdot \mathrm{SO}_{4}{ }^{2-}\right]$ ion pairs, discussed in Section 4.2.

\subsection{Description of thermodynamic properties}

4.4.1 Degree of dissociation and solution composition. In Fig. 1, experimental data for the degree of dissociation of the bisulfate ion and the individual ion molarities are shown as a function of the overall sulphuric acid molarity and compared with the results of our model. In order to calculate the molarity, we use the density of the solution as calculated by the model for the given thermodynamic conditions.
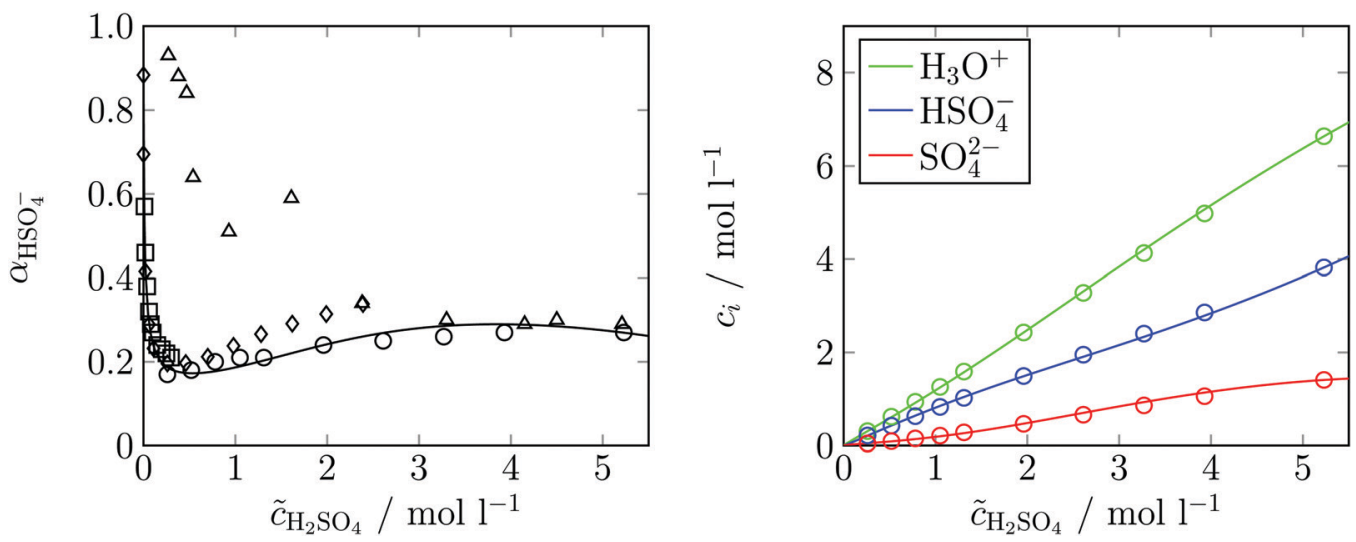

Fig. 1 Degree of dissociation of the bisulphate ion (left) and individual ion molarities (right) as functions of the overall molarity of sulphuric acid in aqueous solution at 298.15 K. Continuous curves: SAFT-VRE Mie calculations, symbols: experimental data from the literature (circles, ${ }^{79}$ squares, ${ }^{78}$ triangles, ${ }^{101}$ diamonds $^{95}$. 
The degree of dissociation data of Hood and Reilly ${ }^{101}$ show considerable scatter and are therefore disregarded in the parameter estimation of the SAFT-VRE Mie model. The other three experimental data sets for $\alpha_{\mathrm{HSO}_{4}{ }^{-}}{ }^{78,79,95}$ are in mutual agreement. It can be seen that an infinitely dilute solution of sulphuric acid contains a negligible fraction of bisulfate ions, with $\alpha_{\mathrm{HSO}_{4}}{ }^{-}$approaching unity. With increasing concentration of the acid, the degree of dissociation quickly falls to a minimum of $\approx 0.17$, indicating that the majority of $\mathrm{HSO}_{4}{ }^{-}$ions do not dissociate, then rises to a maximum of $\approx 0.37$ before again decreasing steadily with increasing acid concentration. The SAFT-VRE Mie model is in excellent agreement with these data. This of course translates to a good representation of the individual ion molarities.

4.4.2 Water activity and mean-ionic activity coefficient. As outlined in Section 2.3.3, using the osmotic coefficient in model development can be misleading when studying weak electrolytes. This is especially the case for aqueous solutions of sulphuric acid which has more than one dissociation step. Instead, the water activity ( $c f$. eqn (29)) is studied here. The water activity and the stoichiometric mean-ionic activity coefficient of sulphuric acid, defined as ( $c f$. eqn (27))

$$
\tilde{\gamma}_{\mathrm{H}_{2} \mathrm{SO}_{4}}^{* \mathrm{~m} \text { stoich }}=\left[\frac{1}{4} \frac{\left(m_{\mathrm{H}_{3} \mathrm{O}^{+}}\right)^{2} m_{\mathrm{SO}_{4}{ }^{2-}}}{\left(\tilde{m}_{\mathrm{H}_{2} \mathrm{SO}_{4}}\right)^{3}}\left(\gamma_{\mathrm{H}_{3} \mathrm{O}^{+}}^{* \mathrm{~m}}\right)^{2} \gamma_{\mathrm{SO}_{4}{ }^{2-}}^{* \mathrm{~m}}\right]^{1 / 3},
$$

are presented as a function of the overall sulphuric acid molality in Fig. 2 .

The water activity is included in the estimation of the model parameters for molalities up to $\tilde{m}_{\mathrm{H}_{2} \mathrm{SO}_{4}} \approx 3 \mathrm{~mol} \mathrm{~kg}{ }^{-1}$. The SAFT-VRE Mie model provides a good description of these data and moreover, the water activities at much higher acid concentrations are also predicted to be in good agreement with the experimental data.

The stoichiometric mean-ionic activity coefficient is not included in the fit and is thus described predictively with the present SAFT-VRE Mie model ( $c f$. Fig. 2, right panel). Despite not considering this property in the model development, the SAFT-VRE Mie predictions are found to be in excellent agreement with the experimental data. The accurate prediction of this property at high temperatures not only highlights the predictive capability of our modelling approach, but also further validates the chosen association scheme.

4.4.3 Vapour pressure and solution density. We now examine two further properties which can be predicted with the SAFT-VRE Mie model: the vapour pressure and the liquid density of aquoeus solutions of sulphuric acid. These are presented as a function of the overall sulphuric acid molarity at different temperatures in Fig. 3.

The vapour pressure is significantly affected by the value of the solvent-solute dispersion interaction. The predictions obtained using our SAFT-VRE Mie model for the vapour pressure of aqueous solutions of sulphuric acid are in excellent agreement with the experimental data across a wide temperature range and up to high acid concentrations, indicating that the dispersion interactions are modelled accurately.

The liquid density is another key property for assessing the performance of our sulphuric acid model since most of the SAFT-VRE Mie parameters with the greatest influence on the density, namely the size and energy parameters of the Mie potential, are either assigned experimental values or set by combining rules. In Fig. 3 a good agreement between the SAFT-VRE Mie predictions and the experimental data for the solution density at different temperatures and concentrations is seen, indicating that suitable ionic diameters have been assigned to the $\mathrm{HSO}_{4}{ }^{-}$and $\mathrm{SO}_{4}{ }^{2-}$ ions, and that the choice of implementing combining rules is appropriate for assigning the dispersion interactions in this system.

\section{Nitric acid}

\subsection{Pure nitric acid model}

Nitric acid $\left(\mathrm{HNO}_{3}\right)$ is a challenging compound to work with, as it undergoes spontaneous decomposition as well as self-ionic dissociation. This unstable chemical behaviour makes the pure acid difficult to obtain and maintain for experimental purposes. In practice the true composition of a quantity of
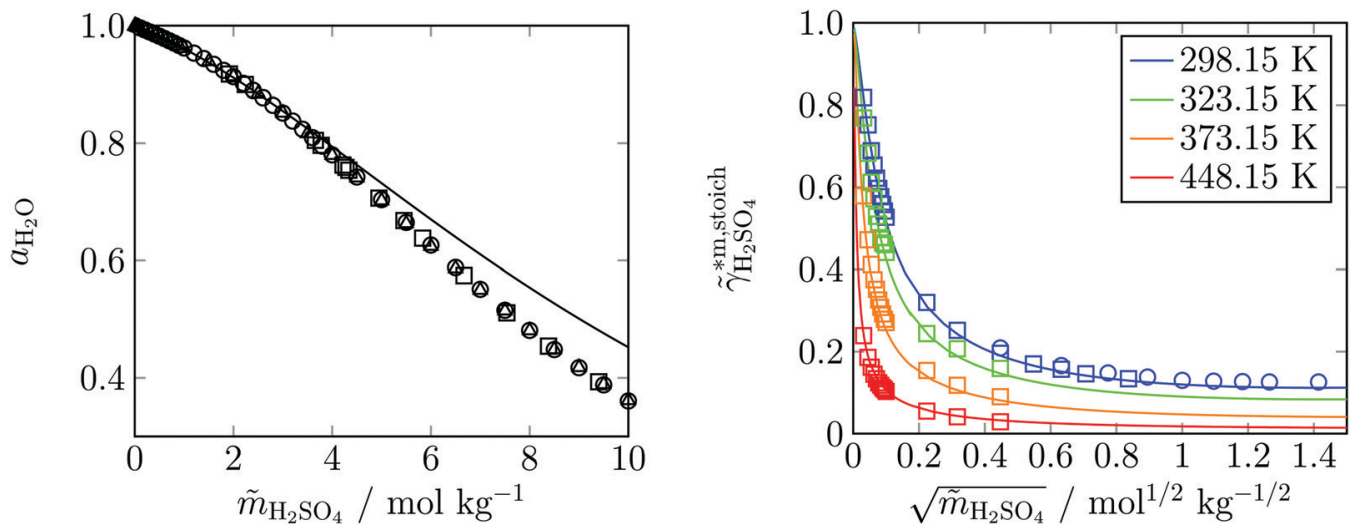

Fig. 2 Activity of water at $298.15 \mathrm{~K}$ (left) and stoichiometric mean-ionic activity coefficient of sulphuric acid at different temperatures (right) as functions of the overall molality of sulphuric acid in aqueous solution. Continuous curves: SAFT-VRE Mie predictions, symbols: experimental data from the

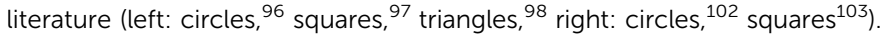



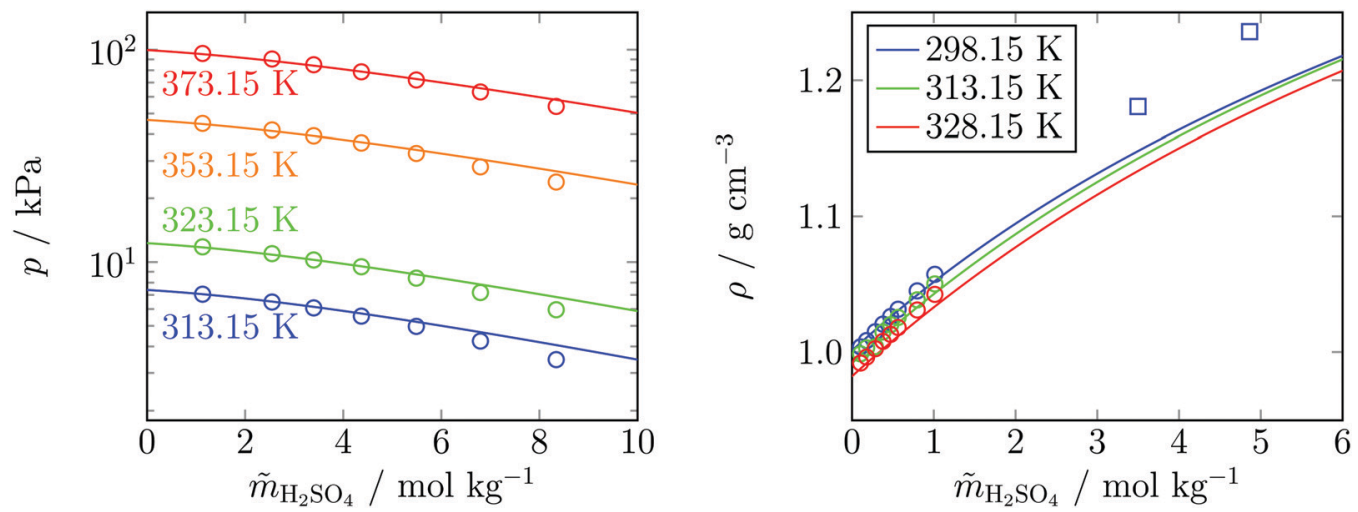

Fig. 3 Vapour pressure (left) and liquid density (right) as functions of the overall molality of sulphuric acid in aqueous solution at different temperatures. Continuous curves: SAFT-VRE Mie prediction, symbols: experimental data from the literature (left: ${ }^{104}$ right: $^{\text {ircles, }}{ }^{88}$ squares $^{105}$ ).

'pure' nitric acid also contains nitrate, nitronium, and hydronium ions, as well as water and nitrogen dioxide. ${ }^{106}$ However, experimental data for nitric acid are not accompanied by any such information regarding the degree to which $\mathrm{HNO}_{3}$ decomposes or ionises, hence it is not possible to take this into account for the purpose of model development. The assumption adopted here is that these reactions may be considered negligible such that experimental data may be taken to correspond to pure nitric acid.

5.1.1 Association scheme. A distinctive characteristic of the $\mathrm{HNO}_{3}$ molecule is its strong affinity to hydrogen bonding. A spectroscopic study by Guillory and Bernstein ${ }^{107}$ has suggested that nitric acid self-associates via intermolecular hydrogen bonding, forming doubly hydrogen bonded cyclic dimers - a structure that Odutola and Dyke ${ }^{108}$ later confirmed. Nitric acid dimerisation is mediated in the SAFT-VRE Mie model via association sites on the $\mathrm{HNO}_{3}$ model. In principle, the dimerisation can be achieved with one donor ('H'-type) site and one acceptor ('e'-type) site (self-association of the donor and acceptor sites is forbidden). However, since the $\mathrm{HNO}_{3}$ model will also be used in aqueous solutions, it is prudent to design the association scheme in such a way as to facilitate its association with water. McCurdy et al. ${ }^{109}$ have concluded through spectroscopic observation and theoretical calculations that $\mathrm{HNO}_{3}$ molecules form stable clusters with up to four water molecules, although they agree with previous work by Canagaratna et al. ${ }^{110}$ that in any given cluster no more than two water molecules are directly bonded to the nitric acid molecule. In order to take into account the thermodynamic influence of these clusters in an effective manner, we implement an association scheme that includes one donor ('H'-type) site and three acceptor ('e'-type) sites on $\mathrm{HNO}_{3}$.

5.1.2 Model development. The SAFT-VRE Mie model for the $\mathrm{HNO}_{3}$ molecule is developed by estimating the model parameters from the vapour pressure and the saturated-liquid density, making use of the whole range of temperatures for which data are available. Experimental data at temperatures higher than $T>373 \mathrm{~K}$ are not available, possibly due to the aforementioned difficulties associated with nitric acid stability. A prediction of the critical properties exists, ${ }^{111}$ but is excluded from the present analysis and discussion as the resulting estimate for the critical temperature is so high that it is likely that the acid would decompose to a large extent at those conditions.

Our optimal model for nitric acid is presented in Table 1. In the development of the model, the attractive Mie exponent is fixed to $\lambda_{\mathrm{a}}=6$ and the number of association sites is assigned as $n_{\mathrm{H}}=1$ and $n_{\mathrm{e}}=3$; all other parameters are characterised by minimisation of the objective function $(c f$. (51)). We find a value for the parameter $m$ which corresponds to a non-spherical geometry, a finding which is in accordance with the planar structure of the $\mathrm{HNO}_{3}$ molecule. ${ }^{106}$ Taking into account the optimised segment diameter $\sigma$, the overall size of the $\mathrm{HNO}_{3}$ molecule is $\sim 26 \%$ larger than the size experimentally determined for the $\mathrm{NO}_{3}{ }^{-}$ion (see Section 5.2.3), which is physically reasonable. In terms of the energetic parameters, the strong self-association energy at short range parallels the expected dimerisation behaviour. The performance of the model is illustrated in Fig. 4 in terms of the vapour pressure and saturated-liquid density of pure nitric acid, in comparison to experimental data.

The SAFT-VRE Mie model calculations are in good agreement with the available experimental data. For both properties, the temperature range for which experimental data are available roughly matches the temperature range for which the corresponding data are available for aqueous solutions of nitric acid, so that altogether, this model provides a good starting point for modelling the aqueous solutions.

\subsection{Aqueous nitric acid}

In aqueous solution, nitric acid dissociates incompletely, yet appreciably, producing a solution containing solvated nitrate ions $\left(\mathrm{NO}_{3}^{-}\right)$, hydronium ions $\left(\mathrm{H}_{3} \mathrm{O}^{+}\right)$, and the molecular acid $\left(\mathrm{HNO}_{3}\right)$. Nitric acid is generally regarded as a 'strong' acid due to its high degree of dissociation at low concentrations, e.g. at room temperature, $\alpha_{\mathrm{HNO}_{3}} \geq 95 \%$ for $\tilde{m}_{\mathrm{HNO}_{3}} \leq 2 \mathrm{~mol} \mathrm{~kg}{ }^{-1}$. Within this range of solution compositions nitric acid could be reasonably approximated as a strong electrolyte. However, in order to model nitric acid across a wide range of compositions it is useful to develop a general model that incorporates speciation. 

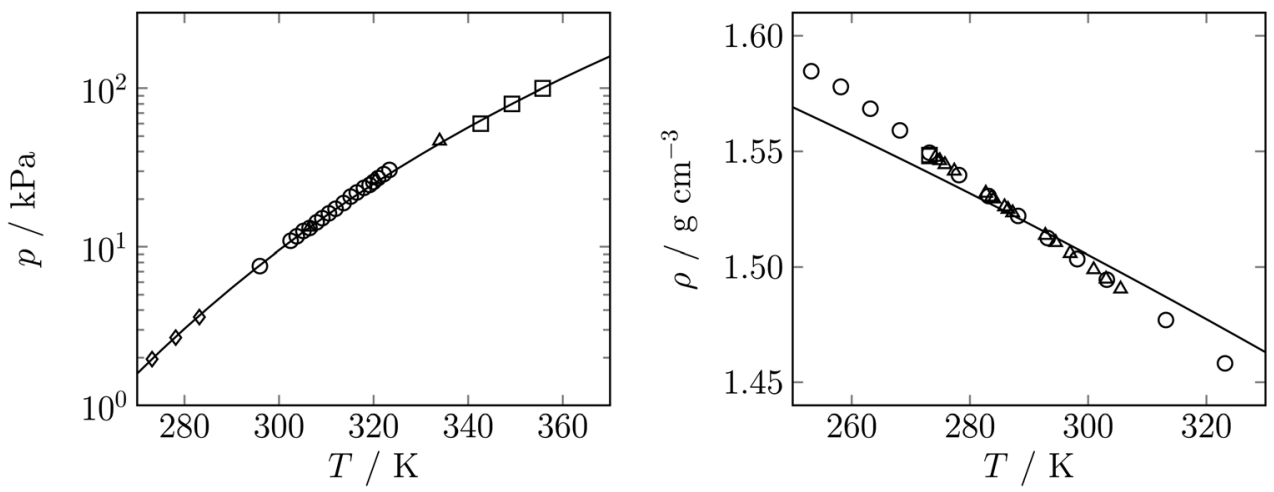

Fig. 4 Vapour pressure (left) and saturated-liquid density (right) of pure nitric acid as functions of the temperature. Only the temperature range in which experimental data are available is shown. No data are available for the saturated-vapour density of nitric acid. Curves: SAFT-VRE Mie predictions, symbols: experimental data from the literature (left: circles, ${ }^{112}$ squares, ${ }^{113}$ triangles, ${ }^{114}$ diamonds, ${ }^{115}$ right: circles, ${ }^{116}$ squares, ${ }^{117}$ triangles $^{118}$ ).

Both approaches are pursued here as a means of demonstrating the benefit of modelling the weak electrolyte explicitly. We use the terms 'strong electrolyte model' and 'weak electrolyte model' to distinguish both approaches in the following discussion.

5.2.1 Dissociation equilibrium. In aqueous solution, nitric acid partially dissociates according to the following protontransfer reaction with water:

$$
\mathrm{HNO}_{3}+\mathrm{H}_{2} \mathrm{O} \stackrel{K_{\mathrm{a}}}{\rightleftharpoons} \mathrm{H}_{3} \mathrm{O}^{+}+\mathrm{NO}_{3}^{-} \text {. }
$$

In the molality scale, the thermodynamic equilibrium constant $K_{\mathrm{a}}$ of this reaction is given by ( $c f$. eqn (19))

$$
K_{\mathrm{a}}(T)=\frac{m_{\mathrm{H}_{3} \mathrm{O}^{+}} m_{\mathrm{NO}_{3}-}}{m_{\mathrm{HNO}_{3}} m^{0}} \frac{\gamma_{\mathrm{H}_{3} \mathrm{O}^{+}}^{* \mathrm{~m}} \gamma_{\mathrm{NO}_{3}{ }^{-}}^{* \mathrm{~m}}}{\gamma_{\mathrm{HNO}_{3}}^{* \mathrm{~m}}},
$$

and at room temperature $\mathrm{p} K_{\mathrm{a}} \approx-1.40$. This thermodynamic equilibrium constant has been studied over a wide temperature range, employing a range of experimental techniques. In an early investigation, Hood and Reilly ${ }^{119}$ determined the thermodynamic equilibrium constant for aqueous nitric acid at three temperatures between $273-343 \mathrm{~K}$ by using proton magnetic resonance to obtain the dissociation quotient of the reaction and then combining this with activity coefficient measurements from previous studies to calculate $K_{\mathrm{a}}$. Using flow calorimetry, Oscarson et al. ${ }^{120}$ obtained $K_{\mathrm{a}}$ for three temperatures between $523-592 \mathrm{~K}$, and later Chlistunoff et al. ${ }^{121}$ measured $K_{\mathrm{a}}$ for nitric acid at $653 \mathrm{~K}$ and $673 \mathrm{~K}$ using UV-vis spectroscopy. Taking an indirect approach, Marshall and Slusher ${ }^{122}$ determined the thermodynamic equilibrium constant of nitric acid in water by measuring the solubility of calcium sulphate in aqueous nitric acid solutions. The measured solubility product for the salt and the known thermodynamic equilibrium constant of the second dissociation step of sulphuric acid were used to deduce $K_{\mathrm{a}}$ for nitric acid by extrapolation. Marshall and Slusher ${ }^{123}$ also used the same approach to obtain $K_{\mathrm{a}}$ for nitric acid from solubility measurements of magnesium sulphate in aqueous nitric acid, with comparable results. In each study the authors proposed a correlation to calculate $K_{\mathrm{a}}$ as a function of temperature; the two correlations provide similar predictions for the thermodynamic equilibrium constant of nitric acid.
In the former publication, the authors included also data from other studies in the regression, thus obtaining a correlation which is applicable for temperatures between 273-623 K:

$$
\log _{10} K_{\mathrm{a}}=5.424-\frac{134.37}{(T / \mathrm{K})}-0.01199(T / \mathrm{K}) \text {. }
$$

Eqn (64) is chosen as the best means for calculating the thermodynamic equilibrium constant of nitric acid in the present work.

5.2.2 Association scheme. The hydration number for nitrate ions in aqueous solution has been reported over the range of 1.3-17.7 based on diffraction measurements in the bulk solution, ${ }^{124,125}$ leading to conflicting interpretations of the ion being either unhydrated or weakly hydrogen bonded to water. By contrast, ab initio theoretical calculations by Howell et al. ${ }^{126}$ suggested that $\mathrm{NO}_{3}{ }^{-}$forms stable clusters with three water molecules, each of which hydrogen bonds to the oxygen atoms on the $\mathrm{NO}_{3}{ }^{-}$ion such that all six lone electron pairs on the ion are occupied. In a subsequent study Wang et al. ${ }^{127}$ demonstrated using photoelectron spectroscopy that the first solvation shell of the nitrate ion consists of three water molecules, and also confirmed Howell's aforementioned hydrogen-bonding scheme between $\mathrm{NO}_{3}{ }^{-}$and $\mathrm{H}_{2} \mathrm{O}$ via density functional theory (DFT) calculations.

Spectroscopic and theoretical studies of hydrogen bonding between molecular nitric acid and water have suggested that $\mathrm{HNO}_{3}$ associates with up to four $\mathrm{H}_{2} \mathrm{O}$ molecules, with the acid ionising upon associating with the fourth water molecule. McCurdy et al. ${ }^{109}$ identified $\mathrm{HNO}_{3}\left(\mathrm{H}_{2} \mathrm{O}\right)_{n}$ clusters with $n=1-3$ using Fourier transform infrared spectroscopy. Using first principles electronic structure calculations, the authors obtained the structures for clusters with $n=1-4$ and showed that for $n=4$ two stable hydrogen bonded clusters are feasible: $\mathrm{HNO}_{3}\left(\mathrm{H}_{2} \mathrm{O}\right)_{4}$ as a global minimum and the solvated ion pair $\left[\mathrm{NO}_{3}{ }^{-}\left(\mathrm{H}_{2} \mathrm{O}\right)_{3} \cdot \mathrm{H}_{3} \mathrm{O}^{+}\right]$as a local minimum. Shortly afterwards, Scott and Wright ${ }^{128}$ studied the same $\mathrm{HNO}_{3}\left(\mathrm{H}_{2} \mathrm{O}\right)_{n}$ clusters using $a b$ initio and DFT molecular orbital calculations. Although these authors proposed a different geometry for the nitrate-hydronium ion pair, the existence of both $\mathrm{HNO}_{3}\left(\mathrm{H}_{2} \mathrm{O}\right)_{4}$ 
and $\left[\mathrm{NO}_{3}{ }^{-}\left(\mathrm{H}_{2} \mathrm{O}\right)_{3} \cdot \mathrm{H}_{3} \mathrm{O}^{+}\right]$species was supported, corresponding to the equilibrium

$$
\mathrm{HNO}_{3}\left(\mathrm{H}_{2} \mathrm{O}\right)_{4} \rightleftharpoons\left[\mathrm{NO}_{3}{ }^{-}\left(\mathrm{H}_{2} \mathrm{O}\right)_{3} \cdot \mathrm{H}_{3} \mathrm{O}^{+}\right] .
$$

However, the species $\left[\mathrm{NO}_{3}{ }^{-}\left(\mathrm{H}_{2} \mathrm{O}\right)_{3} \cdot \mathrm{H}_{3} \mathrm{O}^{+}\right]$has not been experimentally observed and, since it is calculated to be less stable than the $\mathrm{HNO}_{3}\left(\mathrm{H}_{2} \mathrm{O}\right)_{4}$ cluster, it is likely to be an intermediate product of the acid's dissociation. Indeed, Marinkovic et al. ${ }^{129}$ have demonstrated that nitrate ions form contact ion pairs with hydronium ions, in a study using in situ infrared reflection spectroscopy to examine the electric double layer on gold electrodes in nitric acid solutions. Whether the contact ion pairs observed in the double layer would also form in bulk solution remains undetermined.

These studies are taken into consideration to inform the association interactions that may be accounted for in a SAFT-VRE Mie model of aqueous solutions of nitric acid. The hydrogenbonding interactions are straightforwardly assigned following the experimental evidence: three 'e'-type sites are assigned to the $\mathrm{NO}_{3}{ }^{-}$ion. They can in principle interact with the ' $\mathrm{H}$ ' type sites on $\mathrm{H}_{2} \mathrm{O}$ and $\mathrm{H}_{3} \mathrm{O}^{+}$. While the importance of the $\mathrm{NO}_{3}{ }^{-}-\mathrm{H}_{2} \mathrm{O}$ association is apparent from the studies mentioned earlier, the SAFT-VRE Mie framework allows one to investigate the impact of the $\mathrm{NO}_{3}{ }^{-}-\mathrm{H}_{3} \mathrm{O}^{+}$association on the thermodynamic properties of the mixture, thereby probing the existence of the $\left[\mathrm{NO}_{3}{ }^{-}\left(\mathrm{H}_{2} \mathrm{O}\right)_{3} \cdot \mathrm{H}_{3} \mathrm{O}^{+}\right]$ cluster. The association between molecular $\mathrm{HNO}_{3}$ and $\mathrm{H}_{2} \mathrm{O}$ is determined by the interactions of the ' $\mathrm{e}$ ' and ' $\mathrm{H}$ ' type sites on $\mathrm{HNO}_{3}$ with the ' $\mathrm{H}$ ' and 'e' type sites on $\mathrm{H}_{2} \mathrm{O}$, respectively.

\subsubsection{Model development}

5.2.3.1 Objectives. Three target properties are considered in the adjustment of the model parameters ( $c f$. eqn (51)): the first objective is the degree of dissociation of nitric acid, defined as

$$
\alpha_{\mathrm{HNO}_{3}}=\frac{m_{\mathrm{NO}_{3}{ }^{-}}}{m_{\mathrm{HNO}_{3}}+m_{\mathrm{NO}_{3}-}}=\frac{m_{\mathrm{NO}_{3}{ }^{-}}}{\tilde{m}_{\mathrm{HNO}_{3}}}
$$

at $298.15 \mathrm{~K}$ and 1 bar. All available experimental data on the degree of dissociation are considered..$^{76,130-133}$ These data span the entire composition range from pure water to pure nitric acid. As the second objective, vapour-liquid equilibrium data in the nitric-acid-rich region of the phase diagram, i.e., where the overall mole fraction of nitric acid in the liquid phase is $\tilde{x}_{\mathrm{HNO}_{3}} \geq 0.5 \mathrm{~mol} \mathrm{~mol}^{-1}$, is used in the parameter estimation. ${ }^{134-137}$ At these high concentrations, nitric acid remains almost completely in its molecular form ( $c f$. Section 5.3.1), so that these data should be especially sensitive to the parameters characterising the $\mathrm{HNO}_{3}-\mathrm{H}_{2} \mathrm{O}$ interaction. As the third objective, the stoichiometric osmotic coefficient of aqueous solutions of nitric acid for concentration up to 6 molal is employed. ${ }^{138}$ At these relatively low concentrations, nitric acid dissociates almost completely, so that these data should be especially sensitive to the parameters characterising the $\mathrm{NO}_{3}{ }^{-}-\mathrm{H}_{2} \mathrm{O}$ interaction.

5.2.3.2 Like parameters. The diameter $\sigma_{\mathrm{NO}_{3}{ }^{-}}$is assigned according to the value corresponding to the ion's diameter in a crystal lattice, as reported by Marcus. ${ }^{139}$ The corresponding Born diameter $\sigma_{\mathrm{NO}_{3}{ }^{-}}^{\mathrm{Born}}$ is obtained from the molecular-dynamics simulation study of Babu and $\mathrm{Lim},{ }^{57}$ in which the Born cavity diameter of $\mathrm{NO}_{3}{ }^{-}$was calculated to be $10.5 \%$ larger than the ionic diameter chosen here. This relative magnitude of the two sizes for the $\mathrm{NO}_{3}{ }^{-}$ion is in line with the $7 \%$ increase recommended by Rashin and Honig, ${ }^{100}$ hence the value proposed by Babu and Lim is considered to be reasonable. The like-ion dispersion energy $\varepsilon_{\mathrm{NO}_{3}-}$ is obtained by applying the combining rule given by eqn (40). The polarisability ${ }^{69}$ and ionisation potential (negative electron affinity) ${ }^{72}$ of $\mathrm{NO}_{3}{ }^{-}$are reported in Table 4.

5.2.3.3 Unlike parameters. The unlike dispersion energy $\varepsilon_{\mathrm{NO}_{3}{ }^{-}, \mathrm{H}_{3} \mathrm{O}^{+}}$between the nitrate and hydronium ions is calculated with eqn (40), and the unlike energy parameters involving one of the ions and either water or nitric acid $\left(\varepsilon_{\mathrm{H}_{2} \mathrm{O}, \mathrm{NO}_{3}-}, \varepsilon_{\mathrm{HNO}_{3}, \mathrm{H}_{3} \mathrm{O}^{+}}\right.$ and $\varepsilon_{\mathrm{HNO}_{3}, \mathrm{NO}_{3}^{-}}$) using eqn (43), using the parameters given in Tables 1 and 4. The remaining unlike dispersion energy $\varepsilon_{\mathrm{H}_{2} \mathrm{O}, \mathrm{HNO}_{3}}$ between water and nitric acid is estimated by comparison to experimental data ( $c f$. eqn (51)). The reason for this procedure is that the entire composition range from pure water to pure nitric acid is investigated here. The degree of dissociation depends largely on the concentration of nitric acid, which results in different interactions dominating the thermodynamic behaviour of the solution at different compositions.

Additionally, association interactions between $\mathrm{HNO}_{3}-\mathrm{H}_{2} \mathrm{O}$, $\mathrm{NO}_{3}{ }^{-}{ }^{-} \mathrm{H}_{2} \mathrm{O}$ and $\mathrm{NO}_{3}{ }^{-}-\mathrm{H}_{3} \mathrm{O}^{+}$are considered during the model development. Two types of interactions are relevant for the association between the molecular species $\mathrm{HNO}_{3}$ and $\mathrm{H}_{2} \mathrm{O}$, corresponding to the two types of $\mathrm{e}-\mathrm{H}$ site-site interactions: one involves the e-type sites of the oxygen atom of water with the $\mathrm{H}$-type sites of the hydrogen atom in nitric acid; the second involves the e-site types of the oxygen atoms of nitric acid interacting with the H-type sites of the hydrogen atoms of water. Thus, four parameters (two association energy and two bonding volume parameters) need to be determined. As an initial estimate, they are computed from the appropriate combining rules, $c f$. eqn (44) and (45). A sensitivity analysis reveals that the description mainly depends on the strength of the interaction of the e-type sites present in nitric acid and the nitrate ion and the H-type sites preset in water and the hydronium ion. Adjusting the parameters $\varepsilon_{\mathrm{H}_{2} \mathrm{O}, \mathrm{H}-\mathrm{HNO}_{3}, \mathrm{e}}^{\mathrm{HB}}$ and $\varepsilon_{\mathrm{H}_{3} \mathrm{O}^{+}, \mathrm{H}-\mathrm{NO}_{3}^{-}, \mathrm{e}}^{\mathrm{HB}}$ results in an increased strength of these association interactions. The $\mathrm{H}_{2} \mathrm{O}-\mathrm{HNO}_{3}$ association is thus treated as asymmetric, which reflects the proposition that the water molecule associating with the electron site on the nitric acid molecule leads to the ionisation of the acid. The parameters for the $\mathrm{NO}_{3}{ }^{-}-\mathrm{H}_{2} \mathrm{O}$ association interaction are also included in the parameter estimation. The values found for $\varepsilon_{\mathrm{NO}_{3}{ }^{-}-\mathrm{H}_{2} \mathrm{O}}^{\mathrm{OB}^{-}}$and $\mathrm{K}_{\mathrm{NO}_{3}{ }^{-}-\mathrm{H}_{2} \mathrm{O}}^{\mathrm{HB}}$ are characteristic of hydrogen bonding, hence substantiating the proposed hydration of the nitrate ion. Interestingly, including a $\mathrm{NO}_{3}{ }^{-}-\mathrm{H}_{3} \mathrm{O}^{+}$association in the optimisation always yields non-neglible values for both the association energy $\varepsilon_{\mathrm{NO}_{3}{ }^{-}-\mathrm{H}_{3} \mathrm{O}^{+}}^{\mathrm{HB}}$ and the bonding volume $\mathrm{K}_{\mathrm{NO}_{3}{ }^{-}-\mathrm{H}_{3} \mathrm{O}^{+}}^{\mathrm{HB}}$. This would suggest that this association interaction plays an important role the thermodynamic behaviour of the system. In the final model proposed here this interaction has been set to be equal to the 

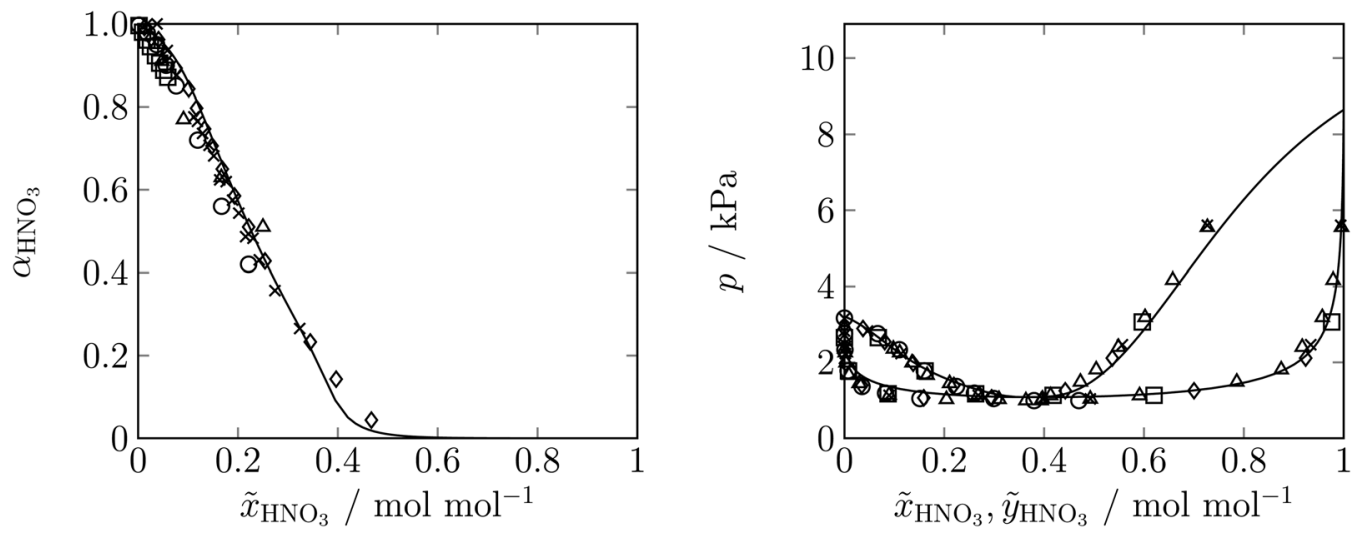

Fig. 5 Degree of dissociation of nitric acid (left) and vapour-liquid equilibrium (right) as functions of the overall mole fraction of nitric acid in aqueous solution at 298.15 K. Curves: SAFT-VRE Mie description, symbols: experimental data from the literature (left: circles, ${ }^{130}$ squares, ${ }^{131}$ triangles, ${ }^{132}$ diamonds, ${ }^{133}$ crosses $^{76}$ right: circles, ${ }^{140}$ squares, ${ }^{134}$ triangles, ${ }^{135}$ diamonds, ${ }^{136}$ crosses $^{137}$ ).

water-nitric acid association interaction. This result supports the proposition of the existence of the $\left[\mathrm{NO}_{3}{ }^{-}\left(\mathrm{H}_{2} \mathrm{O}\right)_{3} \cdot \mathrm{H}_{3} \mathrm{O}^{+}\right]$ species and the proposed equilibrium (65).

\subsection{Description of thermodynamic properties}

5.3.1 Degree of dissociation and vapour-liquid equilibrium. The degree of dissociation of nitric acid and the vapour-liquid equilibrium of water and nitric acid at $298 \mathrm{~K}$ are shown in Fig. 5. It is noted here that both properties are plotted over the overall mole fraction of nitric acid, thereby covering the entire composition range from pure water to pure nitric acid.

The experimental data for $\alpha_{\mathrm{HNO}_{3}}$ are characterised by a steady decrease with increasing concentration of nitric acid; it is seen that $\mathrm{HNO}_{3}$ completely dissociates at high dilution, whereas it completely remains in its molecular form from about an equimolar composition onwards. This behaviour highlights the need to include most of the unlike dispersion energy parameters in the estimation: depending on the concentration, different interactions are dominant. The final SAFT-VRE Mie model captures the experimental data well, with slightly larger deviations for concentrations in the range $\tilde{x}_{\mathrm{HNO}_{3}} \geq 0.3 \mathrm{~mol} \mathrm{~mol}^{-1}$. Nevertheless, the model is found to provide an excellent description of the experimental vapourliquid equilibrium of the mixture, of which only the data points with $\tilde{x}_{\mathrm{HNO}_{3}} \geq 0.5 \mathrm{~mol} \mathrm{~mol}^{-1}$ are used in the model development. The model is able to capture the low-boiling azeotropic behaviour of the system, which is typical of aqueous acids, in excellent agreement with the experimental data. The water-rich side of the phase diagram is described very accurately, with both the azeotropic composition and azeotropic pressure predicted accurately. To the best of our knowledge, this is the first instance of an equation of state model with explicit treatment of the partial dissociation of a weak electrolyte used to describe the entire phase diagram. It would be interesting to assess the performance of the model at other temperatures, however, possibly due to the aforementioned difficulties in handling solutions of $\mathrm{HNO}_{3}$ in the laboratory, such data are scarce and only available at temperatures very close to the one investigated here.
The degree of dissociation and the vapour-liquid equilibrium thus far presented, can only be considered when the partial dissociation is treated explicitly, and molecular nitric acid is incorporated in the model. In the following two sections, we investigate properties that can in principle also be modelled if nitric acid is assumed to be a strong electrolyte that completely dissociates into $\mathrm{H}_{3} \mathrm{O}^{+}$and $\mathrm{NO}_{3}{ }^{-}$ions; i.e., a model that does not account for the presence of nitric acid in the solution. Comparing the results of the two approaches will reveal the benefits of treating the acid as a weak electrolyte.

5.3.2 Stoichiometric osmotic coefficient and mean-ionic activity coefficient. The stoichiometric osmotic coefficient and mean-ionic activity coefficient of nitric acid are defined as (cf. eqns (26) and (31))

$$
\Phi^{\text {stoich }}=-\frac{\ln a_{\mathrm{W}}}{M_{\mathrm{W}} 2 \tilde{m}_{\mathrm{HNO}_{3}}},
$$

and

$$
\tilde{\gamma}_{\mathrm{HNO}_{3}}^{* \mathrm{~m}}=\sqrt{\gamma_{\mathrm{H}_{3} \mathrm{O}^{+}}^{* \mathrm{~m}} \gamma_{\mathrm{NO}_{3}}^{* \mathrm{~m}}} .
$$

Both properties can be calculated assuming the complete ('strong electrolyte') and the partial ('weak electrolyte') dissociation models. The comparison is presented in Fig. 6, where $\Phi^{\text {stoich }}$ and $\tilde{\gamma}_{\mathrm{HNO}_{3}}^{* \mathrm{~m}}$ are shown as functions of the overall nitric acid molality.

The experimental data on the stoichiometric osmotic coefficient for concentrations up to 6 molal are used in the parameter estimation (the $\mathrm{H}_{2} \mathrm{O}-\mathrm{NO}_{3}{ }^{-}$hydrogen bonding interaction). As can be seen, the weak electrolyte model clearly outperforms the strong electrolyte model, both in the case of the stoichiometric coefficient, used in the parameter estimation, and in the case of the predicted mean-ionic activity coefficient as a function of concentration.

5.3.3 Vapour pressure and solution density. The advantage of treating the partial dissociation of the acid explicitly is also evident when studying the vapour pressure and the liquid density of aqueous solutions of nitric acid, which are shown in Fig. 7 as functions of the overall molality of nitric acid. Both 

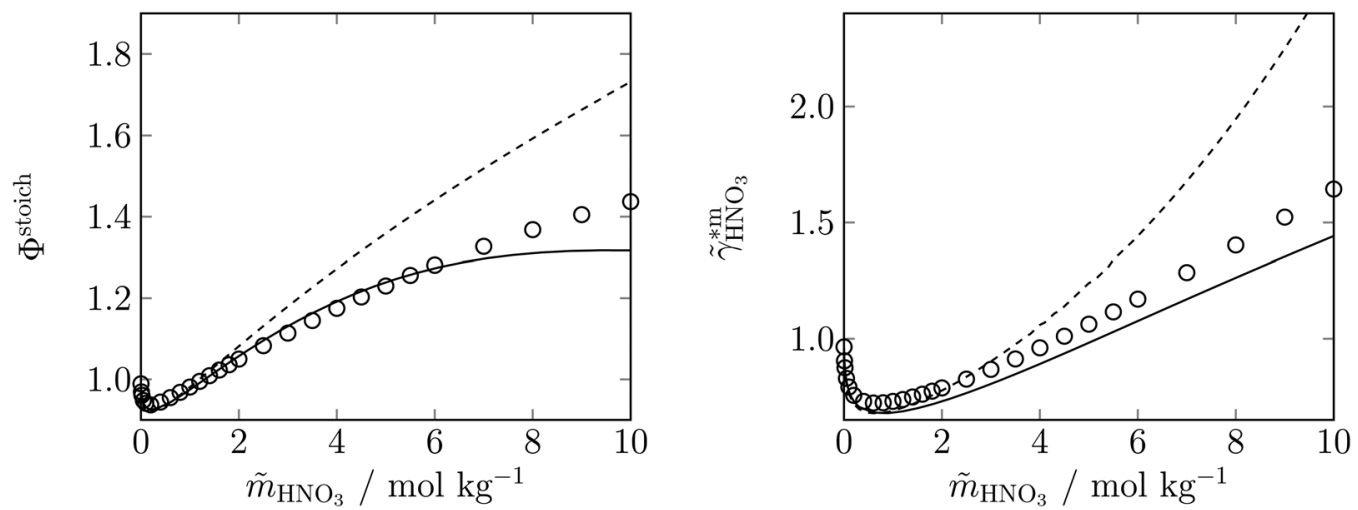

Fig. 6 Stoichiometric osmotic coefficient (left) and mean-ionic activity coefficient (right) as functions of the overall molality of nitric acid in aqueous solution at $298.15 \mathrm{~K}$. Continuous curves: SAFT-VRE Mie description with partial dissociation, dashed curves: SAFT-VRE Mie description with complete dissociation, circles: experimental data from the literature. ${ }^{138}$

properties are predictions obtained with the present model. Note that the concentration range investigated here is rather 'dilute' when compared to the full composition range shown in Section 5.3.1, so the vapour is essentially pure water. This feature enables the calculation of the vapour pressure in the 'strong electrolyte' model.

In Fig. 7 it is evident that the vapour pressure is predicted very accurately when the 'weak electrolyte' model is considered. At low concentrations, the strong electrolyte model performs equally well but increasing deviations become apparent with increasing concentration of nitric acid. Of course, as for the properties presented in the previous section, the refinement of the parameters of the strong electrolyte model would be possible and might lead to a better overall representation; the complete vapour-liquid equilibrium presented in Section 5.3.1 could not, however, be computed with such a model. In terms of the liquid densities, both approaches perform similarly, with some slight differences at higher concentrations. As might have been expected, the partial dissociation only has a minor impact on the density. The good agreement with the experimental data confirms that the diameters assigned for $\mathrm{HNO}_{3}$ (obtained in the parameter estimation of pure $\mathrm{HNO}_{3}$, based on VLE data) and
$\mathrm{NO}_{3}{ }^{-}$(assigned from a literature value of the crystal diameter) are reasonable.

\section{Carbonic acid}

Carbonic acid $\left(\mathrm{H}_{2} \mathrm{CO}_{3}\right)$ differs from our two earlier examples in that the molecular acid is unstable. The stable form is carbon dioxide $\left(\mathrm{CO}_{2}\right)$, which is of particular topical interest for its role as a greenhouse gas. In this context, the dissolution and speciation reaction of carbon dioxide in water, which results in the formation of bicarbonate $\left(\mathrm{HCO}_{3}{ }^{-}\right)$ions, is of relevance in ocean acidification. This slightly acidic character also facilitates capturing carbon dioxide, e.g. in absorption processes using amine solutions. In contrast to the bisulfate ion, the bicarbonate ion is a base, i.e., it donates its proton only in basic solutions.

\subsection{Dissociation equilibrium}

In aqueous solution, carbon dioxide undergoes the following reaction with water:

$$
\mathrm{CO}_{2}(\mathrm{aq})+2 \mathrm{H}_{2} \mathrm{O} \stackrel{K_{\mathrm{a} 1}}{\rightleftharpoons} \mathrm{H}_{3} \mathrm{O}^{+}+\mathrm{HCO}_{3}^{-} \text {. }
$$
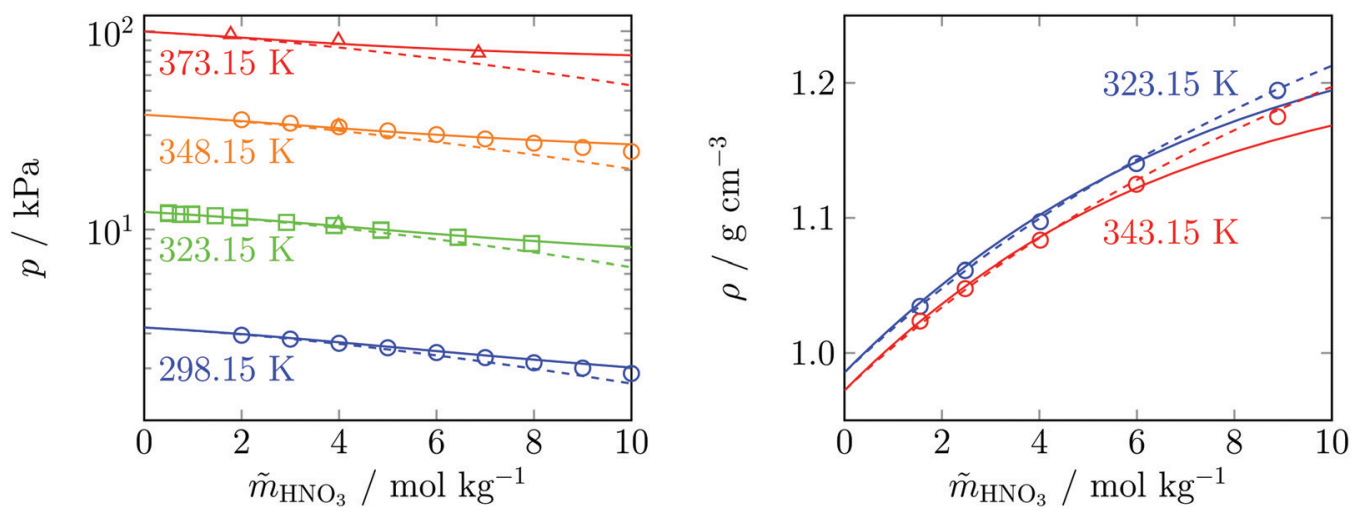

Fig. 7 Vapour pressure (left) and liquid density (right) as functions of the overall molality of nitric acid in aqueous solution at different temperatures. Continuous curves: SAFT-VRE Mie description with partial dissociation, dashed curves: SAFT-VRE Mie description with complete dissociation, symbols:

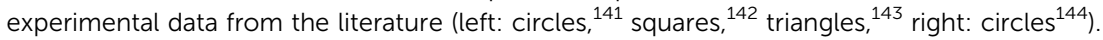


Subsequently, the bicarbonate anion $\mathrm{HCO}_{3}{ }^{-}$can donate one more proton to form the carbonate anion $\mathrm{CO}_{3}{ }^{2-}$, i.e.,

$$
\mathrm{HCO}_{3}{ }^{-}+\mathrm{H}_{2} \mathrm{O} \stackrel{K_{\mathrm{a} 2}}{\rightleftharpoons} \mathrm{H}_{3} \mathrm{O}^{+}+\mathrm{CO}_{3}^{2-} \text {. }
$$

The corresponding conditions for chemical equilibrium are, $c f$. eqn (19),

$$
K_{\mathrm{a} 1}(T)=\frac{m_{\mathrm{H}_{3} \mathrm{O}^{+}} m_{\mathrm{HCO}_{3}-}}{m_{\mathrm{CO}_{2}} m^{0}} \frac{\gamma_{\mathrm{H}_{3} \mathrm{O}^{+}}^{* m} \gamma_{\mathrm{HCO}_{3}^{-}}^{* m}}{\gamma_{\mathrm{CO}_{2}}^{* m}}
$$

and

$$
K_{\mathrm{a} 2}(T)=\frac{m_{\mathrm{H}_{3} \mathrm{O}^{+}} m_{\mathrm{CO}_{3}{ }^{2-}} \gamma_{\mathrm{H}_{3} \mathrm{O}^{+}}^{* m} \gamma_{\mathrm{CO}_{3}{ }^{2-}}^{* \mathrm{~m}}}{m_{\mathrm{HCO}_{3}-m^{0}}} .
$$

We note in passing that $K_{\mathrm{a} 1}$ refers to $\mathrm{CO}_{2}(\mathrm{aq})$ here; in the literature, sometimes an equilibrium constant with respect to $\mathrm{CO}_{2}$ (gas) is presented in which the Henry's law constant of $\mathrm{CO}_{2}$ in $\mathrm{H}_{2} \mathrm{O}$ is included to account for the necessary dissolution of $\mathrm{CO}_{2}$. However, as we use the SAFT-VRE Mie equation of state here and take the phase equilibrium into account explicitly, this is not necessary.

At ambient temperature, $\mathrm{p} K_{\mathrm{a} 1} \approx 6.35$ and $\mathrm{p} K_{\mathrm{a} 2} \approx 10.32,{ }^{145}$ so that compared to the acids studied in the previous sections $\mathrm{CO}_{2}$ is a 'truly weak' electrolyte. More importantly, with the present approach, the second dissociation step cannot be treated. As $\mathrm{p} K_{\mathrm{a} 2}>7$, a basic solution is required for the carbonate formation, so that data on additional species, other than $\mathrm{H}_{2} \mathrm{O}$ and $\mathrm{CO}_{2}$, would be needed. Thus, only the formation of bicarbonate, i.e., the first dissociation step, is considered here, and a new model for $\mathrm{HCO}_{3}{ }^{-}$is developed.

The thermodynamic equilibrium constant of the bicarbonate formation has been studied over a wide temperature range. Harned and Davis, ${ }^{146}$ Harned and Bonner, ${ }^{147}$ and Curry and Hazelton ${ }^{148}$ carried out electromotive force measurements of aqueous solutions of sodium bicarbonate and extrapolated their results to zero ionic strength to obtain the thermodynamic equilibrium constant in the range $273 \leq T / \mathrm{K} \leq 323$. Over the same temperature range, Näsänen ${ }^{149}$ and Näsänen et al..$^{150}$ measured the $\mathrm{pH}$ of the solution and combined these data with titration determinations. At higher temperatures ( $373 \leq T / \mathrm{K} \leq 523)$, Ryzhenko ${ }^{151}$ and Read ${ }^{152}$ determined the $K_{\mathrm{a} 1}$ from conductivity measurements. The aforementioned data sets were employed by Plummer and Busenberg $^{145}$ to obtain an empirical correlation for $K_{\mathrm{a} 1}$ :

$$
\begin{aligned}
\log _{10} K_{\mathrm{a} 1}= & -356.3094-0.06091964(T / \mathrm{K})+21834.37(\mathrm{~K} / T) \\
& +126.8339 \log _{10}(T / \mathrm{K})-1684915(\mathrm{~K} / T)^{2} .
\end{aligned}
$$

This correlation, which is appropriate in the temperature range $273 \leq T / \mathrm{K} \leq 523$, is used here.

\subsection{Association scheme}

The association and hydration of the $\mathrm{HCO}_{3}{ }^{-}$anion in aqueous solutions have recently been studied, mainly employing quantumchemical methods. Using Car-Parrinello molecular dynamics (MD) simulations, Kumar et al. ${ }^{153}$ showed that on average $\mathrm{HCO}_{3}{ }^{-}$ forms four hydrogen bonds with $\mathrm{H}_{2} \mathrm{O}$. Garand et al. ${ }^{154}$ conducted infrared spectroscopic measurements and analysed them together with electronic structure calculations. They confirmed the hydration number of four and also found that water molecules interact directly with the $\mathrm{CO}_{2}$ moiety of the bicarbonate anion, while binding of water to the hydroxyl group is particularly disfavoured. Dopieralski et al. ${ }^{155}$ used a combination of $a b$ initio MD calculations and acoustic experiments. They evaluated the hydration numbers of $\mathrm{HCO}_{3}{ }^{-}$in the range 5.3-5.6 and also disproved the existence of $\mathrm{HCO}_{3}{ }^{-}$selfassociation, as only minor amounts of $\mathrm{HCO}_{3}{ }^{-}$dimers were found in solution. From their MD simulations, England et al. ${ }^{156}$ have reported a coordination number of 4.26 for $\mathrm{H}_{2} \mathrm{O}$ around $\mathrm{HCO}_{3}{ }^{-}$. Later, Stefansson et al. ${ }^{157}$ found excellent agreement for the $\mathrm{HCO}_{3}{ }^{-} \cdot n \mathrm{H}_{2} \mathrm{O}$ clusters with the work of Garand et al. ${ }^{154}$ and Wen et al. ${ }^{158}$ confirmed with DFT calculations that the first four water molecules prefer to interact with the $\mathrm{CO}_{2}$ moiety of the $\mathrm{HCO}_{3}{ }^{-}$anion. Very recently, Kong et al. ${ }^{159}$ studied the vibration of $\mathrm{HCO}_{3}{ }^{-}$in $\mathrm{HCO}_{3}{ }^{-} \cdot n \mathrm{H}_{2} \mathrm{O}$ clusters with ab initio MD simulations and found water libration for $n \geq 6$.

We use these findings to inform the choice of bonding schemes in our SAFT-VRE Mie approach. As $\mathrm{H}_{2} \mathrm{O}$ is found to associate exclusively with the $\mathrm{CO}_{2}$ moiety of the $\mathrm{HCO}_{3}{ }^{-}$anion, we propose to follow the type of association and the parameters obtained by Papaioannou et al. ${ }^{68}$ for the system $\mathrm{H}_{2} \mathrm{O}+\mathrm{CO}_{2}$ to model the association of $\mathrm{H}_{2} \mathrm{O}+\mathrm{HCO}_{3}{ }^{-}$. To this end, four e-type sites are placed on the $\mathrm{HCO}_{3}{ }^{-}$anion that can only associate with the $\mathrm{H}$-type sites on $\mathrm{H}_{2} \mathrm{O}$, as at most four water molecules are found to associate with one $\mathrm{HCO}_{3}{ }^{-}$anion. The same association interaction is also introduced between the three $\mathrm{H}$-type sites on $\mathrm{H}_{3} \mathrm{O}^{+}$and the $\mathrm{HCO}_{3}{ }^{-}$ion.

\subsection{Model development}

6.3.1 Objectives. The models for sulphuric and nitric acids presented in the previous sections were mainly developed from speciation data. However, as $\mathrm{CO}_{2}$ is a much weaker electrolyte, speciation data are difficult to determine experimentally. Instead, for optimisation we employ a single objective ( $c f$. eqn (51)) closely related to speciation: the $\mathrm{pH}$ of saturated aqueous solutions of $\mathrm{CO}_{2}$, which is defined as

$$
\mathrm{pH}=-\log _{10} a_{\mathrm{H}_{3} \mathrm{O}^{+}}^{* \mathrm{~m}} .
$$

We estimate the model interaction parameters from the experimental pH data at $T=323 \mathrm{~K} .{ }^{160}$

6.3.2 Like parameters. For the $\mathrm{HCO}_{3}{ }^{-}$anion, both the diameter $\sigma_{\mathrm{HCO}_{3}{ }^{-}}$and the Born diameter $\sigma_{\mathrm{HCO}_{3}{ }^{-}}^{\mathrm{Born}}$ are taken from the work of Marcus. ${ }^{139,161}$ The dispersion energy parameter $\varepsilon_{\mathrm{HCO}_{3}-}$ is calculated with the Hudson-McCoubrey rule, $c f$. eqn (40). The ionisation potential of $\mathrm{HCO}_{3}{ }^{-}$is estimated as its adiabatic electron detachment energy taken from Wang and Xantheas, ${ }^{73}$ and the polarisability is approximated as that of the $\mathrm{CO}_{3}{ }^{2-}$ ion from Pyper et al. ${ }^{69} \mathrm{cf}$. Table 4 .

6.3.3 Unlike parameters. The unlike dispersion energies $\varepsilon_{\mathrm{CO}_{2}, \mathrm{H}_{3} \mathrm{O}^{+}}, \varepsilon_{\mathrm{CO}_{2}, \mathrm{HCO}_{3}{ }^{-}}$and $\varepsilon_{\mathrm{H}_{3} \mathrm{O}^{+}, \mathrm{HCO}_{3}{ }^{-}}$are all calculated using the Hudson-McCoubrey rule, $c f$. eqn (40). As discussed earlier, we adopt the association scheme and the corresponding 


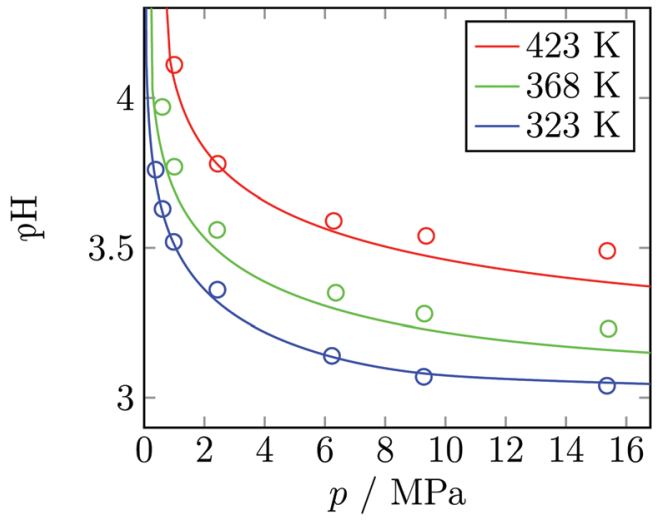

Fig. $8 \mathrm{pH}$ as a function of the total pressure of carbon dioxide in aqueous solution at different temperatures. Continuous curves: SAFT-VRE Mie calculations, circles: experimental data from the literature. ${ }^{160}$

parameters for the $\mathrm{H}_{2} \mathrm{O}-\mathrm{HCO}_{3}{ }^{-}$and $\mathrm{H}_{3} \mathrm{O}^{+}-\mathrm{HCO}_{3}{ }^{-}$association from the $\mathrm{CO}_{2}-\mathrm{H}_{2} \mathrm{O}$ interaction parameterised by Papaioannou et $a l .{ }^{68}$ The only parameter employed in the parameter estimation here is the unlike dispersion energy $\varepsilon_{\mathrm{H}_{2} \mathrm{O}, \mathrm{HCO}_{3}}$, determined from the experimental $\mathrm{pH}$ of aqueous solutions of $\mathrm{CO}_{2}$ at $T=323 \mathrm{~K}$.

\subsection{Description of thermodynamic properties}

6.4.1 pH. We start our discussion with the property used in the determination of parameters, namely the $\mathrm{pH}$ of saturated aqueous solutions of $\mathrm{CO}_{2}$. This property is shown at several temperatures as a function of the total pressure in Fig. 8.

As can be seen in Fig. 8, the present model, using only one adjustable parameter, is capable of accurately representing the $\mathrm{pH}$ at the temperature considered in the fit $(T=323 \mathrm{~K})$. The same parameter can be used to predict the temperature dependence of the $\mathrm{pH}$ in very good agreement with the experimental data.

6.4.2 Gas solubility. In Fig. 9, the VLE of the $\mathrm{H}_{2} \mathrm{O}+\mathrm{CO}_{2}$ mixture, including the dissociation of $\mathrm{CO}_{2}$ modelled as described in the previous section, is shown. The total pressure of the system is plotted as a function of the overall $\mathrm{CO}_{2}$ mole fraction in the liquid and vapour phases, respectively, for various temperatures.
The SAFT-VRE Mie model represents both the liquid and vapour phase compositions as a function of the pressure in good agreement with the experimental data. It should be noted that the agreement is mostly due to the original parameterisation of the $\mathrm{H}_{2} \mathrm{O}-\mathrm{CO}_{2}$ interaction carried out by Papaioannou et $a l^{68}$ Nevertheless, it is remarkable that the SAFT-VRE Mie model is able to represent the maximum in the vapour-phase composition $\tilde{y}_{\mathrm{CO}_{2}}$ as a function of pressure.

The model developed here for solutions of carbon dioxide in water, including the speciation of the acid, demonstrates the strong physical basis of our SAFT-VRE Mie approach. The association scheme, and corresponding parameters, have been obtained considering the interactions of carbon dioxide and bicarbonate with water. Using only one adjustable parameter, an excellent description of the $\mathrm{pH}$ of the solution is obtained over a broad temperature range. The model developed here for the bicarbonate ion will be of great use in applications involving systems with additional reacting components in future work.

\section{Conclusions}

The SAFT-VRE Mie equation of state has been applied to aqueous solutions of three important inorganic acids: sulphuric acid, nitric acid, and carbonic acid. Building on experimental information for the thermodynamic equilibrium constant of the dissociation reaction, we demonstrate that SAFT-VRE Mie is a valuable tool for the description of the thermodynamic properties of aqueous solutions of weak electrolytes. As found previously for solutions of strong electrolytes, experimental values can be used to estimate the parameters of the ions. Only few unlike interaction parameters need to be adjusted with respect to experimental data for the speciation and activity or phase equilibrium data, at a single temperature. The SAFT-VRE Mie models obtained in this manner reproduce these training data accurately, and the predictive capability of the approach is highlighted by the quality of description that can be achieved for other properties over a wide temperature range, such as osmotic coefficients, mean-ionic activity coefficients and vapour pressures.
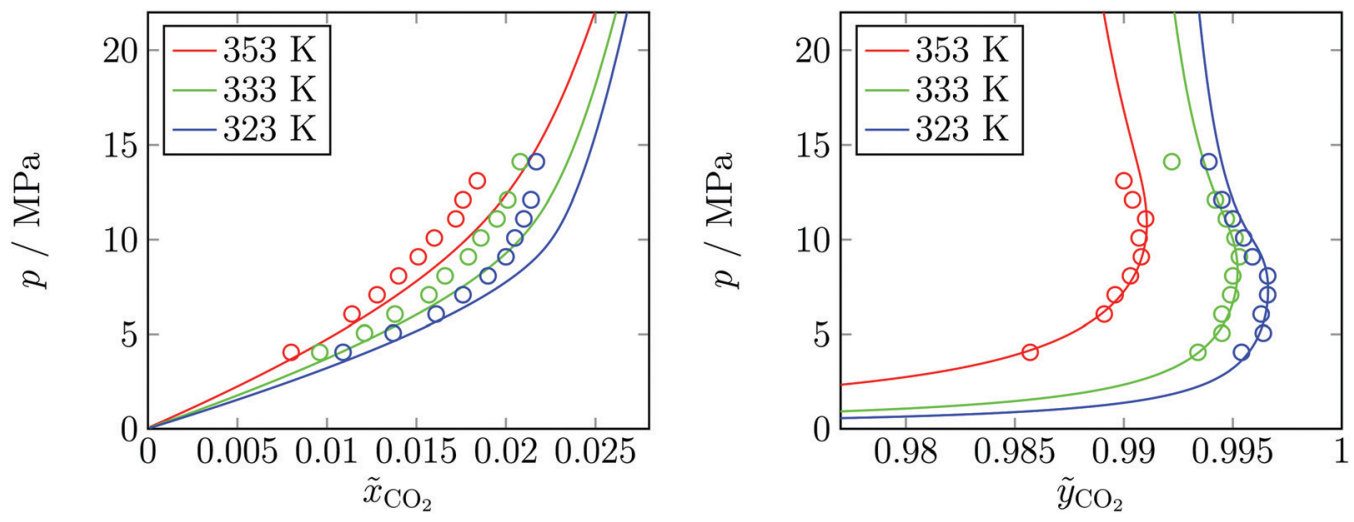

Fig. 9 Pressure as function of the overall mole fraction of carbon dioxide in the liquid phase (left) and the vapour phase (right) for aqueous solutions of carbon dioxide at different temperatures. Continuous curves: SAFT-VRE Mie calculations, circles: experimental data from the literature. ${ }^{162}$ 
The sound physical basis of the SAFT-VRE Mie approach also enables elaborating on ambiguities regarding association interactions in the solutions studied, including hydrogen bonding and ion pairing. In aqueous solutions of sulphuric acid, the SAFT-VRE Mie model reveals that the thermodynamic properties are mainly governed by a strong association of the hydronium ion with the sulfate ion, indicative of the formation of an ion pair. In aqueous solutions of nitric acid, we observe a strong, asymmetric association between water and nitric acid; a strong solvation of the nitrate anion is also found. Finally, aqueous solutions of carbon dioxide can be modelled accurately by assuming that water associates mainly with the $\mathrm{CO}_{2}$ moiety of the bicarbonate anion, confirming quantum mechanical studies from the literature.

In future work, we plan to incorporate this approach in the SAFT- $\gamma$ Mie group-contribution equation of state to develop models of complex organic ions as heteronuclear chains containing charged and uncharged segments, extending our recent work in this area. ${ }^{163}$

\section{Data statement}

Data underlying this article can be accessed on Zenodo at http://doi.org/10.5281/zenodo.3894279, and used under the Creative Commons Attribution license.

\section{Conflicts of interest}

There are no conflicts to declare.

\section{Appendix A: derivation of Prigogine's theorem}

Consider the Gibbs free energy of the solution of an electrolyte $\mathrm{AB}$ in a solvent $\mathrm{W}$. The 'overall' composition point of view leads to

$$
G=\tilde{n}_{\mathrm{AB}} \tilde{\mu}_{\mathrm{AB}}+\tilde{n}_{\mathrm{W}} \tilde{\mu}_{\mathrm{W}}
$$

and the 'true' composition point of view leads to

$$
G=n_{\mathrm{AB}} \mu_{\mathrm{AB}}+n_{\mathrm{W}} \mu_{\mathrm{W}}+n_{\mathrm{A}^{+}} \mu_{\mathrm{A}^{+}}+n_{\mathrm{B}^{-}} \mu_{\mathrm{B}^{-}} .
$$

Inserting the material balances (eqns (2)-(4)) into eqn (76) and rearranging yields

$$
G=\tilde{n}_{\mathrm{AB}} \mu_{\mathrm{AB}}+\tilde{n}_{\mathrm{W}} \mu_{\mathrm{W}}+\left(\nu_{\mathrm{A}^{+}} \mu_{\mathrm{A}^{+}}+\nu_{\mathrm{B}^{-}} \mu_{\mathrm{B}^{-}}-\mu_{\mathrm{AB}}\right) \xi .
$$

In chemical equilibrium, $c f$. eqn (9), the expression in brackets vanishes, so that

$$
G=\tilde{n}_{\mathrm{AB}} \mu_{\mathrm{AB}}+\tilde{n}_{\mathrm{W}} \mu_{\mathrm{W}}
$$

The Gibbs free energy is of course independent of the point of view, so that the 'true' and 'overall' perspective must yield the same value for $G$. Thus, comparing eqn (75) and (78) yields:

$$
\begin{gathered}
\mu_{\mathrm{AB}}=\tilde{\mu}_{\mathrm{AB}} \\
\mu_{\mathrm{W}}=\tilde{\mu}_{\mathrm{W}}
\end{gathered}
$$

\section{Appendix B: derivation of the definition of the stoichiometric mean-ionic activity coefficient}

Consider the dissociation of a weak electrolyte $\mathrm{AB}$ in two ways. In general, one can write for the chemical potential of the electrolyte as

$$
\tilde{\mu}_{\mathrm{AB}}=\tilde{\mu}_{\mathrm{AB}}^{\mathrm{ref} \mathrm{m}}+R T \ln \left[\left(\frac{m_{\mathrm{A}^{+}}}{m^{0}}\right)^{\nu_{\mathrm{A}}}\left(\frac{m_{\mathrm{B}^{-}}}{m^{0}}\right)^{\nu_{\mathrm{B}}}\right]+R T \ln \left[\left(\tilde{\gamma}_{\mathrm{AB}}^{* \mathrm{~m}}\right)^{\nu_{\mathrm{A}}+\nu_{\mathrm{B}}}\right],
$$

which is simply eqn (24). If the electrolyte is formally assumed to dissociate completely (i.e., to stoichiometric composition), the material balances (eqns (2)-(4)) can be inserted into eqn (81) to yield

$$
\begin{aligned}
\tilde{\mu}_{\mathrm{AB}}= & \tilde{\mu}_{\mathrm{AB}}^{\mathrm{ref} \mathrm{m}}+R T \ln \left[\nu_{\mathrm{A}}^{\nu_{\mathrm{A}}} \nu_{\mathrm{B}}^{\nu_{\mathrm{B}}}\left(\frac{\tilde{m}_{\mathrm{AB}}}{m^{0}}\right)^{\nu_{\mathrm{A}}+\nu_{\mathrm{B}}}\right] \\
& +R T \ln \left[\left(\tilde{\gamma}_{\mathrm{AB}}^{* \text { m,stoich }}\right)^{\nu_{\mathrm{A}}+\nu_{\mathrm{B}}}\right],
\end{aligned}
$$

where the exponent 'stoich' is introduced in the mean-ionic activity coefficient to avoid confusion with the corresponding property in eqn (81). The chemical potential of the electrolyte $\mathrm{AB}$ as such must of course be independent of the way the solution is treated formally, so that eqn (81) and (82) have to be equal. The reference terms then cancel to give

$$
\begin{aligned}
& \nu_{\mathrm{A}}^{\nu_{\mathrm{A}}} \nu_{\mathrm{B}}^{\nu_{\mathrm{B}}}\left(\frac{\tilde{m}_{\mathrm{AB}}}{m^{0}}\right)^{\nu_{\mathrm{A}}+\nu_{\mathrm{B}}}\left(\tilde{\gamma}_{\mathrm{AB}}^{* \mathrm{~m}, \text { stoich }}\right)^{\nu_{\mathrm{A}}+\nu_{\mathrm{B}}} \\
& =\left(\frac{m_{\mathrm{A}^{+}}}{m^{0}}\right)^{\nu_{\mathrm{A}}}\left(\frac{m_{\mathrm{B}^{-}}}{m^{0}}\right)^{\nu_{\mathrm{B}}}\left(\tilde{\gamma}_{\mathrm{AB}}^{* \mathrm{~m}}\right)^{\nu_{\mathrm{A}}+\nu_{\mathrm{B}}} .
\end{aligned}
$$

Inserting the definition of the mean-ionic activity coefficient, $c f$. eqn (26), finally yields the desired relation:

$$
\tilde{\gamma}_{\mathrm{AB}}^{* \mathrm{~m}, \text { stoich }}=\left[\frac{1}{\nu_{\mathrm{A}}^{\nu_{\mathrm{A}}} \nu_{\mathrm{B}}^{\nu_{\mathrm{B}}}} \frac{\left(\frac{m_{\mathrm{A}^{+}}}{m^{0}}\right)^{\nu_{\mathrm{A}}}\left(\frac{m_{\mathrm{B}^{-}}}{m^{0}}\right)^{\nu_{\mathrm{B}}}}{\left(\frac{\tilde{m}_{\mathrm{AB}}}{m^{0}}\right)^{\nu_{\mathrm{A}}+\nu_{\mathrm{B}}}}\left(\gamma_{\mathrm{A}^{+}}^{* \mathrm{~m}}\right)^{\nu_{\mathrm{A}}}\left(\gamma_{\mathrm{B}^{-}}^{* \mathrm{~m}}\right)^{\nu_{\mathrm{B}}}\right]^{\frac{1}{\nu_{\mathrm{A}}+\nu_{\mathrm{B}}}} .
$$

\section{Acknowledgements}

The authors are grateful to the Engineering and Physical Sciences Research Council (EPSRC) of the UK for funding to the Molecular Systems Engineering Group through Grants EP/EP016340 and EP/J014958. EF acknowleges funding from the National Nuclear Laboratory and the EPSRC for a Knowledge Transfer Secondment, GL is thankful to Pfizer, and SK to the Qatar National Research Fund for the award of PhD studentships. CSA acknowledges support from the EPSRC via a Leadership Fellowship (EP/J003840/1). AG acknowledges the funding of a Research Chair by the Royal Academy of Engineering and Eli Lilly and Company (RCSRF1819/7/33). 


\section{Notes and references}

1 I. G. Economou and M. D. Donohue, AIChE J., 1991, 37, 1875-1894.

2 R. H. Stokes and R. A. Robinson, J. Solution Chem., 1973, 2, 173-191.

3 X.-H. Lu and G. Maurer, AIChE J., 1993, 39, 1527-1538.

4 H. Zerres and J. M. Prausnitz, AIChE J., 1994, 40, 676-691.

5 X. Lu, L. Zhang, Y. Wang, J. Shi and G. Maurer, Ind. Eng. Chem. Res., 1996, 35, 1777-1784.

6 E. A. Guggenheim, Trans. Faraday Soc., 1960, 56, 1159-1164.

7 C.-C. Chen, Fluid Phase Equilib., 2006, 241, 103-112.

8 D. Beutier and H. Renon, Ind. Eng. Chem. Process Des. Dev., 1978, 17, 220-230.

9 T. J. Edwards, J. Newman and J. M. Prausnitz, AIChE J., 1975, 21, 248-259.

10 T. J. Edwards, G. Maurer, J. Newman and J. M. Prausnitz, AIChE J., 1978, 24, 966-976.

11 K. S. Pitzer and L. F. Silvester, J. Solution Chem., 1976, 5, 269-278.

12 K. S. Pitzer, J. Phys. Chem., 1973, 77, 268-277.

13 P. Debye and E. Hückel, Phys. Z., 1923, 24, 185-206.

14 C.-C. Chen, H. Britt, J. F. Boston and L. B. Evans, AIChE J., 1982, 28, 588-596.

15 H. Renon and J. M. Prausnitz, AIChE J., 1968, 14, 135-144.

16 D. M. Austgen, G. T. Rochelle and C. C. Chen, Ind. Eng. Chem. Res., 1989, 28, 1060-1073.

17 H. Que and C.-C. Chen, Ind. Eng. Chem. Res., 2011, 50, 11406-11421.

18 C. Achard, C. G. Dussap and J. B. Gros, Fluid Phase Equilib., 1994, 98, 71-89.

19 A. Frendenslund, R. L. Jones and J. M. Prausnitz, AIChE J., 1975, 21, 1086-1099.

20 C. Achard, C. G. Dussap and J. B. Gros, AIChE J., 1994, 40, 1210-1222.

21 P. Wang, A. Anderko and R. D. Young, Fluid Phase Equilib., 2002, 203, 141-176.

22 C. Christensen, B. Sander, A. Frendenslund and P. Rasmussen, Fluid Phase Equilib., 1983, 13, 297-309.

23 K. Thomsen and P. Rasmussen, Chem. Eng. Sci., 1999, 54, 1787-1802.

24 V. Darde, K. Thomsen, W. J. M. Van Well and E. H. Stenby, Energy Procedia, 2009, 1, 1035-1042.

25 G. Soave, Chem. Eng. Sci., 1972, 27, 1197-1203.

26 S. Beret and J. M. Prausnitz, AIChE J., 1975, 21, 1123-1132.

27 P. Vimalchand and M. D. Donohue, Ind. Eng. Chem. Fundam., 1985, 24, 246-257.

28 K. J. Daumn, B. K. Harrison, D. B. Manley and B. E. Poling, Fluid Phase Equilib., 1986, 30, 197-212.

29 G. Jin and M. D. Donohue, Ind. Eng. Chem. Res., 1988, 27, 1737-1743.

30 W. G. Chapman, K. E. Gubbins, G. Jackson and M. Radosz, Fluid Phase Equilib., 1989, 52, 31-38.

31 W. G. Chapman, K. E. Gubbins, G. Jackson and M. Radosz, Ind. Eng. Chem. Res., 1990, 29, 1709-1721.
32 L. F. Cameretti, G. Sadowski and J. M. Mollerup, Ind. Eng. Chem. Res., 2005, 44, 3355-3362.

33 C. Held and G. Sadowski, Fluid Phase Equilib., 2009, 279, 141-148.

34 T. Reschke, S. Naeem and G. Sadowski, J. Phys. Chem. B, 2012, 116, 7479-7491.

35 J. Cassens, A. Prudic, F. Ruether and G. Sadowski, Ind. Eng. Chem. Res., 2013, 52, 2721-2731.

36 C. Held, T. Reschke, S. Mohammad, A. Luza and G. Sadowski, Chem. Eng. Res. Des., 2014, 92, 2884-2897.

37 M. Uyan, G. Sieder, T. Ingram and C. Held, Fluid Phase Equilib., 2015, 393, 91-100.

38 J. Gross and G. Sadowski, Fluid Phase Equilib., 2000, 168, 183-199.

39 J. Gross and G. Sadowski, Ind. Eng. Chem. Res., 2001, 40, 1244-1260.

40 A. Gil-Villegas, A. Galindo, P. J. Whitehead, S. J. Mills, G. Jackson and A. N. Burgess, J. Chem. Phys., 1997, 106, 4168.

41 A. Galindo, L. A. Davies, A. Gil-Villegas and G. Jackson, Mol. Phys., 1998, 93, 241-252.

42 A. Galindo, A. Gil-Villegas, G. Jackson and A. N. Burgess, J. Phys. Chem. B, 1999, 103, 10272-10281.

43 A. Gil-Villegas, A. Galindo and G. Jackson, Mol. Phys., 2001, 99, 531-546.

44 B. H. Patel, P. Paricaud, A. Galindo and G. C. Maitland, Ind. Eng. Chem. Res., 2003, 42, 3809-3823.

45 P. Paricaud, L. Tazi and J.-M. Borgard, Int. J. Hydrogen Energy, 2010, 35, 978-991.

46 J. M. A. Schreckenberg, S. Dufal, A. J. Haslam, C. S. Adjiman, G. Jackson and A. Galindo, Mol. Phys., 2014, 112, 2339-2364.

47 M. Born, Z. Phys., 1920, 1, 45-48.

48 D. K. Eriksen, G. Lazarou, A. Galindo, G. Jackson, C. S. Adjiman and A. J. Haslam, Mol. Phys., 2016, 114, 2724-2749.

49 T. Lafitte, A. Apostolakou, C. Avendaño, A. Galindo, C. S. Adjiman, E. A. Müller and G. Jackson, J. Chem. Phys., 2013, 139, 154504.

50 V. Papaioannou, T. Lafitte, C. Avendaño, C. S. Adjiman, G. Jackson, E. A. Müller and A. Galindo, J. Chem. Phys., 2014, 140, 054107.

51 S. Dufal, T. Lafitte, A. J. Haslam, A. Galindo, G. N. I. Clark, C. Vega and G. Jackson, Mol. Phys., 2015, 113, 948-984.

52 S. Dufal, T. Lafitte, A. J. Haslam, A. Galindo, G. N. I. Clark, C. Vega and G. Jackson, Mol. Phys., 2018, 116, 283-285.

53 M. L. Michelsen and J. M. Mollerup, Thermodynamic Models: Fundamentals \& Computational Aspects, Tie-Line Publications, Holte, Denmark, 2nd edn, 2007.

54 I. Prigogine and R. Defay, Chemical Thermodynamics, Longmans, Green and Co. LTD, London and Harlow, 1954.

55 L. Blum, J. Chem. Phys., 1974, 61, 2129.

56 L. Blum, Mol. Phys., 1975, 30, 1529-1535.

57 C. S. Babu and C. Lim, J. Phys. Chem. B, 1999, 103, 7958-7968.

58 C. Satheesan Babu and C. Lim, Chem. Phys. Lett., 1999, 310, 225-228. 
59 I. Nakamura, J. Phys. Chem. B, 2018, 122, 6064-6071.

60 A. J. Haslam, A. Galindo and G. Jackson, Fluid Phase Equilib., 2008, 266, 105-128.

61 G. H. Hudson and J. McCoubrey, Trans. Faraday Soc., 1960, 56, 761-766.

62 V. Papaioannou, C. S. Adjiman, G. Jackson and A. Galindo, Fluid Phase Equilib., 2011, 306, 82-96.

63 S. Dufal, V. Papaioannou, M. Sadeqzadeh, T. Pogiatzis, A. Chremos, C. S. Adjiman, G. Jackson and A. Galindo, J. Chem. Eng. Data, 2014, 59, 3272-3288.

64 A. Levy, D. Andelman and H. Orland, J. Chem. Phys., 2013, 139, 164909.

65 A. Levy, D. Andelman and H. Orland, J. Chem. Phys., 2018, 149, 109901.

66 X. Duan and I. Nakamura, Soft Matter, 2015, 11, 3566-3571.

67 B. Maribo-Mogensen, G. M. Kontogeorgis and K. Thomsen, J. Phys. Chem. B, 2013, 117, 10523-10533.

68 V. Papaioannou, F. Calado, T. Lafitte, S. Dufal, M. Sadeqzadeh, G. Jackson, C. S. Adjiman and A. Galindo, Fluid Phase Equilib., 2016, 416, 104-119.

69 N. C. Pyper, C. G. Pike and P. P. Edwards, Mol. Phys., 1992, 76, 353-372.

70 M. Hou, R. Lu and A. Yu, RSC Adv., 2014, 4, 23078-23083.

71 X.-B. Wang, J. B. Nicholas and L.-S. Wang, J. Phys. Chem. A, 2000, 104, 504-508.

72 J. Berkowitz, W. A. Chupka and D. Gutman, J. Chem. Phys., 1971, 55, 2733-2745.

73 X.-B. Wang and S. S. Xantheas, J. Phys. Chem. Lett., 2011, 2, 1204-1210.

74 R. A. Robinson and R. H. Stokes, Electrolyte Solutions, Butterworths, London, 2nd edn, 1968.

75 T. F. Young, Rec. Chem. Prog., 1951, 12, 81-95.

76 H. S. Harned and B. B. Owen, The Physical Chemistry of Electrolytic Solutions, Reinhold, New York, 3rd edn, 1958.

77 S. L. Clegg, J. A. Rard and K. S. Pitzer, J. Chem. Soc., Faraday Trans., 1994, 90, 1875-1894.

78 J. T. Edward and I. C. Wang, Can. J. Chem., 1965, 43, 2867-2871.

79 H. Chen and D. E. Irish, J. Phys. Chem., 1971, 75, 2672-2681.

80 R. A. Cox, Ü. L. Haldna, K. L. Idler and K. Yates, Can. J. Chem., 1981, 59, 2591-2598.

81 D. E. Irish and H. Chen, J. Phys. Chem., 1970, 74, 3796-3801.

82 A. G. Dickson, D. J. Wesolowski, D. A. Palmer and R. E. Mesmer, J. Phys. Chem., 1990, 94, 7978-7985.

83 H. F. Holmes and R. E. Mesmer, J. Chem. Thermodyn., 1992, 24, 317-328.

84 K. S. Pitzer, R. N. Roy and L. F. Silvester, J. Am. Chem. Soc., 1977, 99, 4930-4936.

85 H. Sippola, Thermochim. Acta, 2012, 532, 65-77.

86 H. Sippola, J. Chem. Eng. Data, 2013, 58, 3009-3032.

87 Y. Matsushima and A. Okuwaki, Bull. Chem. Soc. Jpn., 1988, 61, 3344-3346.

88 J. K. Hovey and L. G. Hepler, J. Chem. Soc., Faraday Trans., 1990, 86, 2831-2839.

89 D. A. Knopf, B. P. Luo, U. K. Krieger and T. Koop, J. Phys. Chem. A, 2003, 107, 4322-4332.
90 T. F. Young, L. F. Maranville and H. M. Smith, The Structure of Electrolyte Solutions, John Wiley, New York, 1959.

91 P. A. H. Wyatt, Trans. Faraday Soc., 1960, 56, 490-497.

92 D. Fraenkel, J. Phys. Chem. B, 2012, 116, 11662-11677.

93 T. I. Yacovitch, T. Wende, L. Jiang, N. Heine, G. Meijer, D. M. Neumark and K. R. Asmis, J. Phys. Chem. Lett., 2011, 2, 2135-2140.

94 X.-B. Wang, J. B. Nicholas and L.-S. Wang, J. Chem. Phys., 2000, 113, 10837-10840.

95 R. E. Lindstrom and H. E. Wirth, J. Phys. Chem., 1969, 73, 218-223.

96 J. A. Rard, A. Habenschuss and F. H. Spedding, J. Chem. Eng. Data, 1976, 21, 374-379.

97 S. Shankman and A. R. Gordon, J. Am. Chem. Soc., 1939, 61, 2370-2373.

98 B. R. Staples, J. Phys. Chem. Ref. Data, 1981, 10, 779-798.

99 G. A. Krestov, Thermodynamics of Solvation, Ellis Horwood, England, 1st edn, 1991.

100 A. A. Rashin and B. Honig, J. Phys. Chem., 1985, 89, 5588-5593.

101 G. C. Hood and C. A. Reilly, J. Chem. Phys., 1957, 27, 1126-1128.

102 H. Majima and Y. Awakura, Metall. Trans. B, 1988, 19, 347-354.

103 M. R. Schoenberg, S.-C. Yen and T. W. Chapman, J. Solution Chem., 2015, 44, 1339-1357.

104 A. Bosen and H. Engels, Fluid Phase Equilib., 1988, 43, 213-230.

105 E. Königsberger, L.-C. Königsberger, I. Szilágyi and P. M. May, J. Chem. Eng. Data, 2009, 54, 520-525.

106 N. N. Greenwood and A. Earnshaw, Chemistry of the Elements, Elsevier (Elsevier Butterworth-Heinemann, Oxford), 2nd edn, 1997.

107 W. A. Guillory and M. L. Bernstein, J. Chem. Phys., 1975, 62, 1058-1060.

108 J. A. Odutola and T. R. Dyke, J. Chem. Phys., 1978, 68, 5663-5665.

109 P. R. McCurdy, W. P. Hess and S. S. Xantheas, J. Phys. Chem. A, 2002, 106, 7628-7635.

110 M. Canagaratna, J. A. Phillips, M. E. Ott and K. R. Leopold, J. Phys. Chem. A, 1998, 102, 1489-1497.

111 Design Institute for Physical Properties, Sponsored by AIChE, DIPPR Project 801 - Full Version, Design Institute for Physical Property Research/AIChE, 2005; 2008; 2009; 2010; 2011; 2012; 2015; 2016.

112 T. Marnac and M. Enjalbert, Chim. Ind., Genie Chim., 1967, 98, 1047-1051.

113 J. Prošek, Collect. Czech. Chem. Commun., 1967, 32, 2397-2404.

114 F. Rivenq, Bull. Soc. Chim. Fr., 1959, 822-826.

115 G. L. Wilson and F. D. Miles, Trans. Faraday Soc., 1940, 35, 356-363.

116 G. L. Antipenko, E. S. Beletskaya and A. G. Krylova, $Z h$. Prikl. Khim., 1958, 31, 859-863.

117 B. Fine, J. Chem. Eng. Data, 1962, 7, 91-94.

118 S. A. Stern and W. B. Kay, J. Am. Chem. Soc., 1954, 76, 5353-5354. 
119 G. C. Hood and C. A. Reilly, J. Chem. Phys., 1960, 32, 127-130.

120 J. L. Oscarson, S. E. Gillespie, R. M. Izatt, X. Chen and C. Pando, J. Solution Chem., 1992, 21, 789-801.

121 J. Chlistunoff, K. J. Ziegler, L. Lasdon and K. P. Johnston, J. Phys. Chem. A, 1999, 103, 1678-1688.

122 W. L. Marshall and R. Slusher, J. Inorg. Nucl. Chem., 1975, 37, 1191-1202.

123 W. L. Marshall and R. Slusher, J. Inorg. Nucl. Chem., 1975, 37, 2165-2170.

124 J. F. Hinton and E. S. Amis, Chem. Rev., 1971, 71, 627-674.

125 H. Ohtaki and T. Radnai, Chem. Rev., 1993, 93, 1157-1204.

126 J. M. Howell, A. M. Sapse, E. Singman and G. Snyder, J. Phys. Chem., 1982, 86, 2345-2349.

127 X.-B. Wang, X. Yang, L.-S. Wang and J. B. Nicholas, J. Chem. Phys., 2002, 116, 561-570.

128 J. R. Scott and J. B. Wright, J. Phys. Chem. A, 2004, 108, 10578-10585.

129 N. S. Marinković, J. J. Calvente, A. Kloss, Z. Kováčová and W. R. Fawcett, J. Electroanal. Chem., 1999, 467, 325-334.

130 A. Ruas, P. Pochon, J.-P. Simonin and P. Moisy, Dalton Trans., 2010, 39, 10148-10153.

131 O. Redlich, R. W. Duerst and A. Merbach, J. Chem. Phys., 1968, 49, 2986-2994.

132 D. E. Irish and O. Puzic, J. Solution Chem., 1981, 10, 377-393.

133 N. Minogue, E. Riordan and J. R. Sodeau, J. Phys. Chem. A, 2003, 107, 4436-4444.

134 R. Flatt and F. Benguerel, Helv. Chim. Acta, 1962, 45, 1765-1772.

135 M. A. Yakimov and V. Y. Mishin, Radiokhimiya, 1964, 6, 523-527.

136 M. A. Yakimov and V. Y. Mishin, Radiokhimiya, 1964, 6, 543-554.

137 M. A. Yakimov and V. Y. Mishin, Zh. Neorg. Khim., 1967, 12, 1054-1063.

138 W. J. Hamer and Y.-C. Wu, J. Phys. Chem. Ref. Data, 1972, 1, 1047-1100.

139 Y. Marcus, Chem. Rev., 1988, 88, 1475-1498.

140 M. A. Yakimov, V. Y. Mishin and E. V. Zalkind, Zh. Neorg. Khim., 1966, 11, 1934-1940.

141 R. Haas, K. H. Dücker and H. A. Küppers, Ber. Bunsen-Ges., 1965, 69, 97-109.
142 R. J. Lemire, C. P. Brown and A. B. Campbell, J. Chem. Eng. Data, 1985, 30, 421-424.

143 E. Sepp and G. Rayalo, Proc. Acad. Sci. Est. SSR, Chem., 1978, 27, 117-119.

144 V. Granzhan and S. Laktionova, Russ. J. Phys. Chem., 1975, 49, 1448.

145 L. N. Plummer and E. Busenberg, Geochim. Cosmochim. Acta, 1982, 46, 1011-1040.

146 H. S. Harned and R. Davis Jr., J. Am. Chem. Soc., 1943, 65, 2030-2037.

147 H. S. Harned and F. T. Bonner, J. Am. Chem. Soc., 1945, 67, 1026-1031.

148 J. Curry and C. L. Hazelton, J. Am. Chem. Soc., 1938, 60, 2773-2776.

149 R. Näsänen, Acta Chem. Scand., 1947, 1, 204-209.

150 R. Näsänen, P. Meriläinen and K. Lappänen, Acta Chem. Scand., 1961, 15, 913-918.

151 B. N. Ryzhenko, Geochemistry, 1963, 151-164.

152 A. J. Read, J. Solution Chem., 1975, 4, 53-70.

153 P. P. Kumar, A. G. Kalinichev and R. J. Kirkpatrick, J. Phys. Chem. B, 2009, 113, 794-802.

154 E. Garand, T. Wende, D. J. Goebbert, R. Bergmann, G. Meijer, D. M. Neumark and K. R. Asmis, J. Am. Chem. Soc., 2010, 132, 849-856.

155 P. D. Dopieralski, A. Burakowski, Z. Latajka and I. Olovsson, Chem. Phys. Lett., 2011, 507, 89-95.

156 A. H. England, A. M. Duffin, C. P. Schwartz, J. S. Uejio, D. Prendergast and R. J. Saykally, Chem. Phys. Lett., 2011, 514, 187-195.

157 A. Stefansson, K. H. Lemke, P. Benezeth and J. Schott, Geochim. Cosmochim. Acta, 2017, 198, 271-284.

158 H. Wen, G.-L. Hou, Y.-R. Liu, X.-B. Wang and W. huag, Phys. Chem. Chem. Phys., 2016, 18, 17470-17482.

159 X. Kong, S.-T. Sun, L. Jiang and Z.-F. Liu, Phys. Chem. Chem. Phys., 2018, 20, 4571-4578.

160 C. Peng, J. P. Crawshaw, G. C. Maitland, J. P. M. Trusler and D. Vega-Maza, J. Supercrit. Fluids, 2013, 82, 129-137.

161 Y. Marcus, J. Chem. Soc., Faraday Trans., 1991, 87, 2995-2999.

162 A. Bamberger, G. Sieder and G. Maurer, J. Supercrit. Fluids, 2000, 17, 97-110.

163 S. Di Lecce, G. Lazarou, S. H. Khalit, G. Jackson, C. S. Adjiman, A. Galindo and L. McQueen, $R S C A d v$, 2019, 9, 38017-38031. 